\title{
Decarbonization of Distribution Transformers Based on Current Reduction: Economic and Environmental Impacts
}

\author{
Vicente León-Martínez *, Clara Andrada-Monrós, Laura Molina-Cañamero, Jorge Cano-Martínez (D) and \\ Elisa Peñalvo-López (D)
}

Citation: León-Martínez, V.; Andrada-Monrós, C.;

Molina-Cañamero, L.; Cano-Martínez, J.; Peñalvo-López, E. Decarbonization of Distribution Transformers Based on Current Reduction: Economic and Environmental Impacts. Energies 2021, 14, 7207. https://doi.org/10.3390/ en14217207

\section{Academic Editors:}

Fernando Morgado-Dias and Dalia Štreimikienè

Received: 30 August 2021

Accepted: 19 October 2021

Published: 2 November 2021

Publisher's Note: MDPI stays neutral with regard to jurisdictional claims in published maps and institutional affiliations.

Copyright: (c) 2021 by the authors. Licensee MDPI, Basel, Switzerland. This article is an open access article distributed under the terms and conditions of the Creative Commons Attribution (CC BY) license (https:// creativecommons.org/licenses/by/ $4.0 /)$.
Institute for Energy Engineering, Universitat Politècnica de València, Camino de Vera 14, 46022 Valencia, Spain; claanmon@etsii.upv.es (C.A.-M.); laumocaa@etsii.upv.es (L.M.-C.); jorcama2@etsii.upv.es (J.C.-M.); elpealpe@upvnet.upv.es (E.P.-L.)

* Correspondence: vleon@die.upv.es; Tel.: +34-96-387-95-92

\begin{abstract}
Well-known industrial practice efficiency improvement techniques, such as reactive compensation, load balancing, and harmonic filtering, are used in this paper to reduce energy losses in distribution transformers, and therefore, to decrease carbon dioxide emissions and economic costs in the operation of these transformers. Load balancing is carried out by monitoring the values of the angles of the active and reactive components of the vector unbalanced power. Likewise, the application of Order 3/2020 of the Spanish National Markets and Competition Commission is described, in detail, for the calculation of the economic costs derived from the transformer energy losses caused by the load currents and the penalties due to transformer energy deliveries with capacitive power factors. Finally, all these improvement techniques are applied to determine savings in carbon dioxide emissions and costs on the electricity bill of an actual $1000 \mathrm{kVA}$ distribution transformer that supplies a commercial and night-entertainment area. The results of this application case reveal that cost reductions due to energy loss savings are modest, but the reduction in carbon dioxide emissions and the savings in penalties for capacitive reactive supplies are significant.
\end{abstract}

Keywords: transformer losses; transformer efficiency; oil-filled distribution transformer; capacitive penalizations; environmental assessment

\section{Introduction}

Power transformers have energy consumptions, which are manifested in both load and no-load operations [1-4]. These consumptions are invested in raising the temperature of the core and the windings. Therefore, these are energy losses and give rise to economic costs for the owners of these transformers or grid operators (utilities), and also cause environmental costs due to emissions of greenhouse gases $\left(\mathrm{CO}_{2}, \mathrm{NO}_{\mathrm{x}}\right.$, and $\left.\mathrm{SO}_{\mathrm{x}}\right)$ into the atmosphere [1-5].

The economic costs of transformer losses are substantiated, in Spain, by the billing energy component (FE), which is one component of the electricity bill. Electric power prices are set by Circular 3/220 of the Spanish National Markets and Competition Commission [6], which establishes the methodology for calculating electricity transmission and distribution tolls. Costs to the environment are measured in kilograms (or tons) of emissions of carbon dioxide and other gases. The relationship between these emissions and the electrical energy consumed depends, each year, on the electrical mix; that is, on the percentage between the electrical energy generated by conventional power plants, using all types of fossil fuels, and the clean energy (green energy) produced by renewable power plants. The last known value of the emission factor was $0.241 \mathrm{~kg}$ of carbon dioxide emissions per $\mathrm{kWh}$ of energy consumed, in the year 2019, in Spain [7], although the emission factor in the United States reached, in that year, a value of $0.709 \mathrm{~kg} \mathrm{CO}_{2} / \mathrm{kWh}$ [8].

Due to the large number of transformers installed in electrical distribution networks [9], as well as the uninterrupted operation of these machines throughout their 25 to 40 years of useful life, the remarkable relevance that transformer energy losses have 
on energetic sustainability, the circular economy and people's health has been recognized. The United for Efficiency (U4E) initiative, promoted by the UN Environment Agency, estimates that reducing energy losses by improving the efficiency of transformers could achieve energy savings of 750 TWh and reductions of 450 tons of greenhouse gas emissions by the year 2040 [1]. Currently, the Spanish grid operator Endesa has achieved annual energy savings of 5.5 MWh, replacing some of its current $400 \mathrm{kVA}$ distribution transformers with other more efficient ones, but with the same power, and built according to the Commission Regulations (EU) No. 548/2014 [10] and No. 1783/2019 [11]. The replacement of these transformers was carried out within the framework of the Effitrafo Project [2].

The great economic and environmental benefits of improving the efficiency of transformers have encouraged the adaptation of transformer regulations, such as those indicated in [12-15], and their replacement by new efficient transformer regulations [10,11,16-20]. International organizations have developed programs to promote the use of efficient transformers, such as what the European Copper Institute (IEC) has been doing, since 2005, within the European Galileo Program [2]. Likewise, governments have encouraged network operators to replace their inefficient transformers with others that are more environmentally friendly [5], and improve the efficiency of their actual transformers and reduce their load energy losses when these transformers cannot be replaced. The last aspect is the main goal of this paper.

The legislative actions that different governments are taking to replace inefficient transformers are described in detail in [21]. The replacement of transformers implies economic investments for the network operators, which can be paid back in a period of between 2 and 5 years, as indicated in [1,2]. However, some grid operators may not be prepared to assume the necessary investments for the change of all their transformers. In this case, in-load energy-loss reduction could be an interesting short-term option. Additionally, the reduction of energy losses in inefficient transformers increases their useful life and improves the operation of the electrical networks $[3,4,9,22,23]$.

In this paper, the benefits from utilities derived from reducing energy losses on distribution transformers caused by inefficient customers are analyzed, without replacing these transformers for others that are more efficient, and therefore without modifying the value of the core power losses. Specifically, the present paper focuses on:

(1) Determining the power losses caused in distribution transformers by the currents flowing through their windings, as well as the amount of carbon dioxide emissions and economic costs and penalizations due to these losses, and;

(2) Obtaining savings in energy losses, carbon dioxide emissions, and economic costs resulting from applying industrial compensation techniques that minimize reactive, unbalanced, and distorted currents flowing through the transformer windings.

To accomplish these goals, the secondary currents of delta-star transformers are decomposed in Section 2 into positive-sequence fundamental active and reactive currents, fundamental unbalanced currents, and non-fundamental currents, applying Fourier series and Fortescue's theorem [24], and the load power losses derived from these currents are expressed in that section. In Section 3 of this paper, several well-known compensation techniques are applied to minimize reactive, unbalanced, and distortion currents and power losses. and thus to evaluate savings of economic costs and carbon dioxide emissions in the transformer resulting from these compensation techniques.

The application of the procedure for improving the efficiency of distribution transformers described in Section 3 is very cheap. Indeed, reducing energy losses, carbon dioxide emissions, and economic costs and penalizations caused by reactive currents only needs to connect and disconnect, with only a three-phase switch, the capacitor banks available in all transformation houses, which can cause capacitive supplies due to over-compensation overall in periods of small active power consumptions. The effects caused by imbalances can be minimized by properly distributing the loads between the three windings of the transformer secondary. This load sharing can be achieved easily and at no additional cost using a novel technique described in Section 3. Likewise, reduction of effects caused by 
distortions can be minimized by connecting coils in series with each phase of the capacitor banks, if necessary. These coils are very cheap as well.

Section 4 describes Circular 3/2020 of the Spanish National Markets and Competition Commission, which summarizes energy prices in Spain, hourly billing periods, and types of days. Likewise, in this section, expressions to determine penalizations for capacitive consumptions are established.

Compensation techniques described in Section 3 for improving sustainability of distribution transformers, by reducing the RMS values of their currents, are applied in Section 5 . In this section, savings in energy losses, carbon dioxide emissions, and economic costs of a $1000 \mathrm{kVA}$ oil-filled distribution transformer connected to the $20 \mathrm{kV}$ distribution network that supplies energy to an actual commercial and night-entertainment area close to the city of Valencia (Spain) are evaluated. Finally, the conclusions are presented in Section 6.

\section{Load Power Loss Components in Power Transformers}

The transformer load losses are energy consumptions, caused by Joule's effect, due to the circulation of currents through the transformer windings $[19,20,25,26]$. Thus, the load power losses are expressed as follows:

$$
P_{c}=r_{c c} \cdot \sum_{z=A, B, C} I_{z}^{2}
$$

The most efficient transformers are those formed by windings of high conductivity materials, and therefore with small short-circuit resistance $\left(r_{c c}\right)$. For the calculation of the short-circuit resistance, it is recommended to use the temperature correction factor for load losses, indicated in [2,17-19].

According to the following current decomposition included in the IEEE Standard 1459-2010 [27]:

$$
I_{z}^{2}=I_{1 z}^{2}+I_{h z}^{2}=I_{a+}^{2}+I_{r+}^{2}+I_{-}^{2}+I_{0}^{2}+I_{h z}^{2}
$$

which results from applying Fourier series and Fortescue's theorem [24] to the line currents of three-phase circuits $(z=A, B, C)$. Then, the following components of the load losses of the transformer are determined:

$$
P_{c}=P_{c a+}+P_{c r+}+P_{c u}+P_{c h}
$$

where $P_{c a+}$ and $P_{c r+}$ are the transformer power losses caused by the fundamental-frequency positive-sequence active and reactive power deliveries, respectively; $P_{c u}$ is the transformer power losses due to the current imbalances; and $P_{c h}$ is the load losses caused by nonfundamental frequency currents. This model is used by the energy loss calculator (Figure 1) included in the Fluke 435 Series II analyzer [28], which will be used for the measurements made in the application case in Section 5.

Power losses due to the fundamental-frequency positive-sequence active power $\left(P_{c a+}\right)$ are due to the fundamental-frequency positive-sequence active currents $\left(I_{a+}\right)$ that are flowing through the transformer coils. Its value is obtained as follows:

$$
P_{c a+}=3 r_{c c} \cdot I_{a+}^{2}
$$

Power losses due to the fundamental-frequency positive-sequence reactive power $\left(P_{c r+}\right)$ occur due to the fundamental-frequency positive-sequence reactive currents $\left(I_{r+}\right)$ flowing through the transformer windings:

$$
P_{c r+}=3 r_{c c} \cdot I_{r+}^{2}
$$




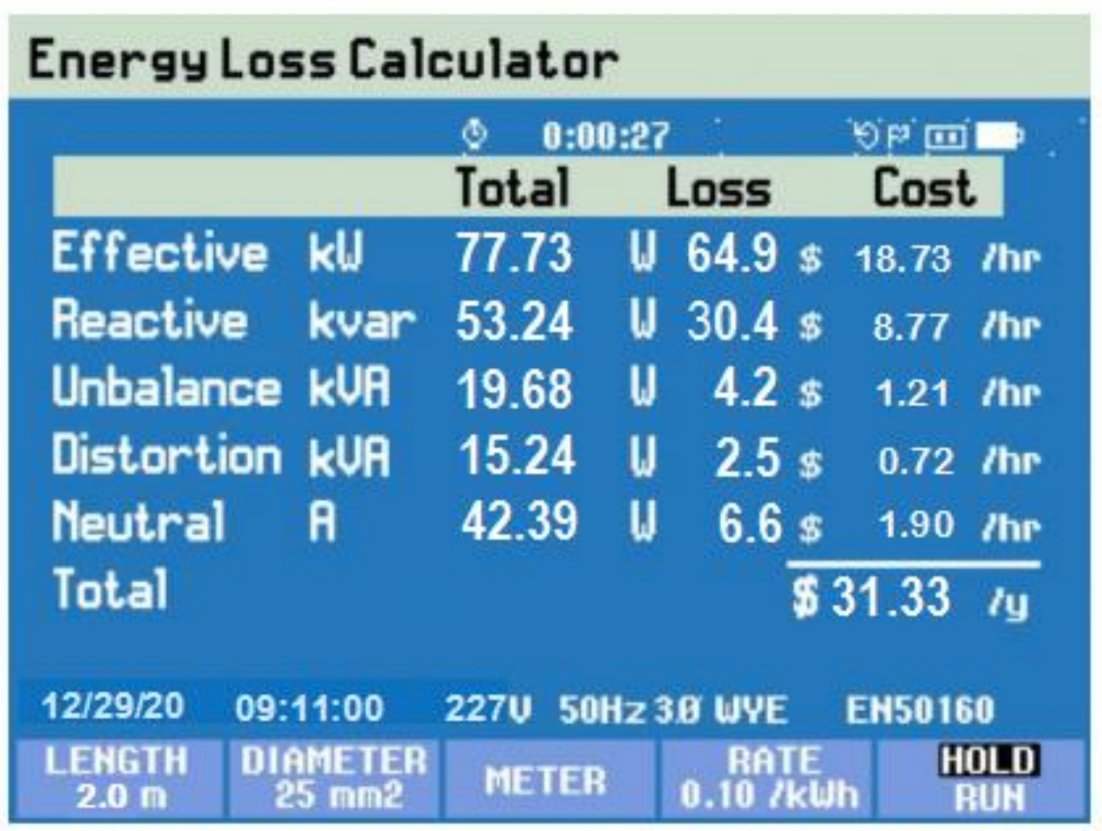

Figure 1. The Energy Loss Calculator screen from the Fluke 435 Series II analyzer.

Power losses due to load imbalances $\left(P_{c u}\right)$ are caused by the circulation of fundamentalfrequency unbalanced currents $\left(I_{u z}\right)$ in each phase $(z=A, B, C)$ of the transformer windings. These currents are of fundamental-frequency negative- $\left(I_{-}\right)$and zero- $\left(I_{0}\right)$ sequences, such that:

$$
P_{c u}=r_{c c} \cdot \sum_{z=A, B, C} I_{u z}^{2}=3 r_{c c} \cdot\left(I_{-}^{2}+I_{0}^{2}\right)
$$

Power losses due to the distorted currents $\left(P_{c h}\right)$ are caused by the circulation of currents of non-fundamental frequency $\left(I_{h z}\right)$ through the windings of the transformers:

$$
P_{c h}=r_{c c} \cdot \sum_{z=A, B, C} I_{h z}^{2}=r_{c c} \cdot \sum_{z=A, B, C}\left(I_{z}^{2}-I_{1 z}^{2}\right)
$$

where $I_{z}$. is the RMS value of the currents in each phase of the transformers $(z=A, B, C)$; and $I_{1 z}$ is the RMS value of the $50-60 \mathrm{~Hz}$ fundamental currents in each phase and the RMS values of the non-fundamental currents in each phase.

$$
I_{h z}=\sqrt{\sum_{n \neq 1}^{\infty} I_{n z}^{2}}
$$

\section{Procedure to Reduce Load Power Losses in Distribution Transformers}

The efficiency of a given transformer, in service, can be improved by canceling or reducing the value of the components of the power losses due to the non-active components of the secondary currents in that transformer, such as the power losses caused by the reactive currents $\left(P_{c r+}\right)$, the unbalanced currents $\left(P_{c u}\right)$, and the distorted currents $\left(P_{c h}\right)$. Power losses caused by the active currents $\left(P_{c a+}\right)$ cannot be reduced, in general, unless it is possible to decrease the energy consumptions of the installations by using more efficient loads. In order to reduce these power losses, different techniques can be implemented according to the following procedures:

1. Reduction of power losses caused by reactive currents $\left(P_{c r+}\right)$ :

These are the main components of the load power losses in distribution transformers, and they can be reduced by applying well-known reactive compensation devices. These 
transformer power losses tend to have a significant savings potential, both in economic costs and in carbon dioxide emissions.

For an optimal reduction of these transformer power losses, as well as the consequent carbon dioxide emissions, the reactive compensation devices should maintain the power factor $(\cos \varphi)$ in the transformer secondary within the limits of 0.95 (inductive) and 0.98 (capacitive), as will be seen in the application case in Section 5. Likewise, maintaining the power factor within the above limits reduces the costs of the electricity bill due to reactive penalties [6].

Power losses caused in the distribution transformers by the reactive currents $\left(P_{c r+}\right)$ are determined as a function of the values of the secondary fundamental-frequency positivesequence line-to-neutral voltages $\left(V_{+}\right)$and the fundamental-frequency positive-sequence reactive power $\left(Q_{+}\right)$, according to the following expression:

$$
P_{c r+}=\frac{1}{3} r_{c c} \cdot\left(\frac{Q_{+}}{V_{+}}\right)^{2}
$$

where the value of the short-circuit resistance of the transformers $\left(r_{c c}\right)$ is firstly calculated as follows:

$$
r_{c c}=P_{c N} \cdot\left(\frac{V_{20}}{S_{N}}\right)^{2}
$$

where $V_{20}$ is the RMS value of the secondary line-to-line voltages in empty conditions; $P_{c N}$ is the transformer's rated load power loss value adapted by the temperature correction factor, indicated in [2,17-19]; and $S_{N}$ is the transformer's rated power.

In electrical networks with slightly unbalanced and distorted voltages (where $T H D_{V} \%<5 \%$ ), which are the most common, the transformer power losses caused by reactive currents can be obtained, with a great practical approximation, using the total reactive power $\left(Q \approx Q_{+}\right)$in expression (9), and by determining $V_{+}$as a function of the line-to-neutral voltages $\left(V_{A N}, V_{B N}, V_{C N}\right)$ measured on the secondary of the transformer, as follows:

$$
V_{+} \approx \frac{1}{3}\left(V_{A N}+V_{B N}+V_{C N}\right)
$$

2. Reduction of transformer power losses due to unbalanced currents $\left(P_{\mathcal{c u}}\right)$ :

Transformer power losses caused by current imbalances are determined by (6), and can be reduced by distributing active and reactive power consumptions equally among the three secondary phases of the transformer. To determine the value and the phase in which the unbalances are most important, a mathematical tool can be used. This tool is the unbalance power vector $\left(\overrightarrow{S_{u}}\right)$, which has been described in detail in $[29,30]$. This quantity has two components, which determine the unbalanced powers caused by the imbalances of active currents $\left(\overrightarrow{S_{\text {uip }}}\right)$ and by the imbalances of reactive currents $\left(\overrightarrow{S_{\text {uiq }}}\right)$, respectively.

The value of $\overrightarrow{S_{\text {uip }}}$ can be approximately obtained, in practice, as follows:

$$
\overrightarrow{S_{\text {uip }}} \approx P_{A}+a^{2} P_{B}+a P_{C}=S_{\text {uip }} \angle \alpha_{p}
$$

where the set $\left(P_{A}, P_{B}, P_{C}\right)$ is the active powers measured in each phase of the secondary windings. The importance of the active current imbalances is determined by the module of value of the module of $\overrightarrow{S_{\text {uip }}}$ in Equation (12), whereas the phase or phases in which the active current imbalances are most important is indicated by the angle $\left(\alpha_{p}\right)$ of $\overrightarrow{S_{u i p}}$.

Likewise, the value of $\overrightarrow{S_{u i q}}$ can be approximately obtained, in practice, as follows:

$$
\overrightarrow{S_{u i q}} \approx Q_{A}+a^{2} Q_{B}+a Q_{C}=S_{u i q} \angle \alpha_{q}
$$


where the set $\left(Q_{A}, Q_{B}, Q_{C}\right)$ is the reactive powers measured in each phase of the secondary windings. The importance of the reactive current imbalances is determined by the value of the module of $\overrightarrow{S_{u i q}}$ in Equation (13), whereas the phase or phases in which the reactive current imbalances are most important is defined by the angle $\left(\alpha_{q}\right)$ of $\overrightarrow{S_{u i q}}$.

The angles $\alpha_{p}$ and $\alpha_{q}$ can have values between $0^{\circ}$ and $360^{\circ}$; therefore, they define a circle with three sectors (Figure 2). Each sector corresponds to the zone of influence of a phase $(A, B, C)$ of the three-phase electrical network. The zone of influence of phase $\mathrm{A}$ occupies the circular sector between $+60^{\circ}$ and $-60^{\circ}$ (green sector in Figure 2); its main axis is in the $0^{\circ}$ spatial position (Figure 2). The zone of influence of phase $B$ occupies the circular sector between $-60^{\circ}$ and $\mp 180^{\circ}$ (blue sector in Figure 2); its main axis is in the spatial position $-120^{\circ}$ (Figure 2). The zone of influence of phase $C$ occupies the circular sector between $\pm 180^{\circ}$ and $+60^{\circ}$ (red sector in Figure 2); its main axis is in the spatial position $+120^{\circ}$ (Figure 2 ).

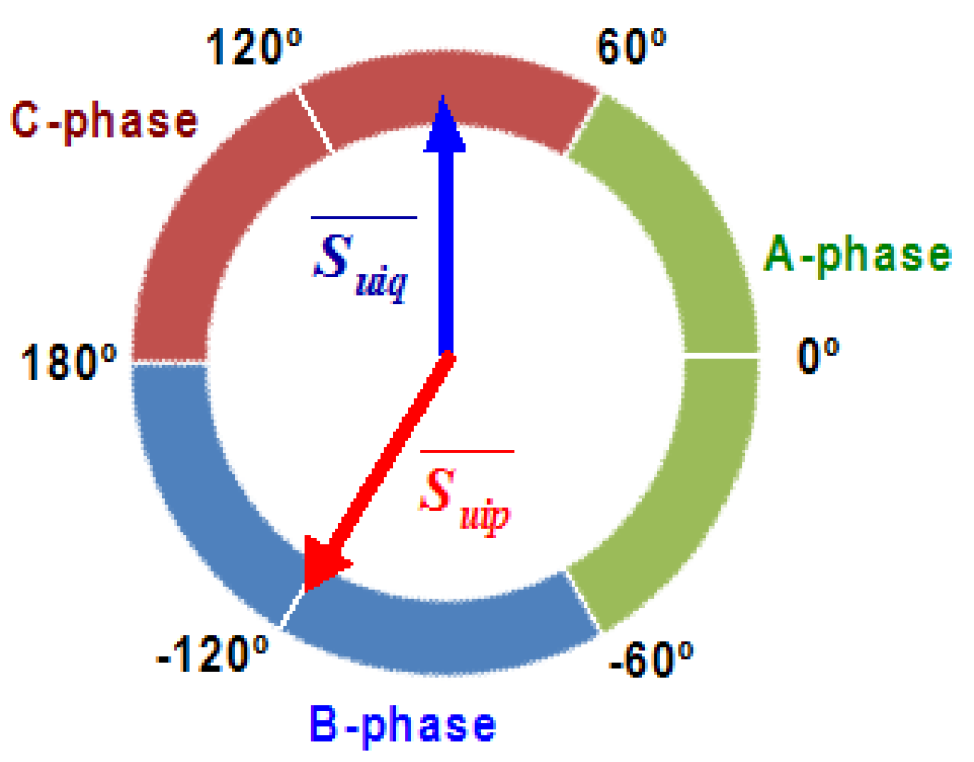

Figure 2. Representation of the vector unbalanced power components: $\overrightarrow{S_{\text {uip }}}$ (red vector) and $\overrightarrow{S_{\text {uiq }}}$ (blue vector).

In order to improve the reader's understanding of this new concept, if the angle $\alpha_{p}$ (or $\alpha_{q}$ ) is $0^{\circ}$, the highest value of active power (or reactive power) occurs in phase A, while the active (or reactive) powers in the phases $\mathrm{B}$ and $\mathrm{C}$ are equal to and less than $P_{A}$ (or $Q_{A}$ ). If $\alpha_{p}$ (or $\left.\alpha_{q}\right)$ is $-120^{\circ}, P_{B}\left(\right.$ or $\left.Q_{B}\right)$ has the highest value, and $P_{A}=P_{C}\left(\right.$ or $Q_{A}=Q_{C}$ ). If $\alpha_{p}\left(\right.$ or $\left.\alpha_{q}\right)$ is $+120^{\circ}, P_{C}\left(\right.$ or $\left.Q_{C}\right)$ has the highest value, and $P_{A}=P_{B}\left(\right.$ or $\left.Q_{A}=Q_{B}\right)$.

In the example shown in Figure 2, the highest active power is found in phase $B$, because the angle $\alpha_{p}=-120^{\circ}$; whereas the highest reactive power occurs in phase $C$, but the reactive powers in the other two phases are not equal $\left(Q_{A}>Q_{B}\right)$, because $\alpha_{q}=90^{\circ}$ $\left(\overrightarrow{S_{\text {uiq }}}\right.$ is in the sector of phase C, close to the boundary with phase A and far from the sector of phase B).

3. Reduction of transformer power losses caused by distorted currents $\left(P_{c h}\right)$ :

These losses can be minimized in distribution transformers with the use of three-phase harmonic filters connected to the secondary of distribution transformers. If the secondary currents of the transformer are highly distorted, the use of active filters is necessary. If the secondary currents of the transformer are slightly distorted and their harmonics are of well-defined frequencies, it is enough to use first-order passive filters tuned to each of the harmonic frequencies. 
The value of the capacitance $\left(C_{n}\right)$ of the capacitor of each first-order passive filter is obtained while considering that the filters must compensate all or part of the reactive power of the installations supplied by the transformer, according to the equation:

$$
C_{n}=\left(1-\frac{1}{n^{2}}\right) \cdot \frac{Q_{c n+}}{3 w_{1} \cdot V_{+}^{2}}
$$

where $n=f_{n} / f_{1}$ is the order of the harmonic to be filtered, $w_{1}=2 \pi f_{1}$ is the pulsation of the currents at the fundamental frequency $\left(f_{1}\right), Q_{c n+}$ is the reactive power that the filter must supply, and $V_{+}$is the voltage of positive sequence and fundamental frequency, determined with a very good approximation by (11).

The value of the inductance $\left(L_{n}\right)$ of the coil of each first-order filter is obtained by applying the resonance condition for the pulsation $\left(w_{n}=n \cdot w_{1}\right)$ of the harmonic to be filtered, namely:

$$
L_{n}=\frac{1}{w_{n}^{2} \cdot C_{n}}
$$

Now, we should check that these values of $C_{n}$ and $L_{n}$ do not give rise to parallel resonance, verifying that none of the existing harmonic frequencies is $f_{r p}=1 / 2 \pi \sqrt{\left(L_{c c}+L_{n}\right) \cdot C_{n}}$, where $L_{c c}$ is the short-circuit inductance of the transformer.

By choosing very good quality coils, with quality factors $\left(q=w_{1} \cdot L_{n} / r_{n}\right)$ greater than 100 , the decrease in non-fundamental frequency currents can be reduced by $95 \%$, which represents a $90 \%$ decrease in losses due to transformer loading caused by distorted currents.

\section{Costs for Energy Losses and Penalizations for Supplies with Capacitive Power Factors}

Energy losses in distribution transformers constitute additional consumptions of active power. These energies result in economic costs, which are determined in Spain by the term of energy billing depending on the energy prices (Table 1), transport and distribution tolls (Table 2) and hourly billing periods (Table 3) [6]:

$$
F E=\sum_{p=1}^{p=i} T e_{p} \cdot W_{p}
$$

where:

- $\quad F E=$ invoiced energy, in euros;

- $T e_{p}=$ price of the energy in the hourly period $\mathrm{p}$, expressed in euros per $\mathrm{kWh}$ (Table 1);

- $W_{p}=$ energy lost by the transformer in the hourly period $\mathrm{p}$, expressed in $\mathrm{kWh}$;

- $\quad i=$ number of hourly periods of transport and distribution tolls (Table 1).

Table 1. Prices of energy in Spain, in euros per $\mathrm{kWh}$, for each hourly period and type of transport and distribution toll $\left(\mathrm{Te}_{\mathrm{p}}\right)$, corresponding to the year 2021.

\begin{tabular}{lcccccc}
\hline \multirow{2}{*}{ Tolls } & \multicolumn{7}{c}{ Hourly Periods } \\
\cline { 2 - 7 } & $\mathbf{P 1}$ & $\mathbf{P 2}$ & $\mathbf{P 3}$ & $\mathbf{P 4}$ & $\mathbf{P 5}$ & P6 \\
\hline 2.0 TDA & 0.108701 & 0.021740 & 0.005435 & - & - & - \\
3.0 TDA & 0.060598 & 0.044887 & 0.024239 & 0.012120 & 0.007769 & 0.004848 \\
6.1 TDA & 0.032950 & 0.024407 & 0.013180 & 0.006590 & 0.004224 & 0.002636 \\
6.2 TDA & 0.015460 & 0.011452 & 0.006184 & 0.003092 & 0.001982 & 0.001237 \\
6.3 TDA & 0.012673 & 0.009387 & 0.005069 & 0.002535 & 0.001625 & 0.001014 \\
6.4 TDA & 0.004815 & 0.003566 & 0.001926 & 0.000963 & 0.000617 & 0.000385 \\
\hline
\end{tabular}


Table 2. Voltage and power limits corresponding to each transport and distribution toll.

\begin{tabular}{|c|c|c|c|c|c|c|}
\hline & \multicolumn{6}{|c|}{ Transport and Distribution Tolls } \\
\hline & 2.0 TDA & 3.0 TDA & $\begin{array}{c}\text { 6.1 TDA } \\
\text { (NT1) }\end{array}$ & $\begin{array}{c}\text { 6.2 TDA } \\
\text { (NT2) }\end{array}$ & $\begin{array}{c}\text { 6.3 TDA } \\
\text { (NT3) }\end{array}$ & $\begin{array}{c}\text { 6.4 TDA } \\
\text { (NT4) }\end{array}$ \\
\hline Voltage $(\mathrm{kV})$ & $V \leq 1$ & $V \leq 1$ & $\begin{array}{c}1<V< \\
30\end{array}$ & $\begin{array}{c}30 \leq V< \\
72.5\end{array}$ & $\begin{array}{c}72.5 \leq \\
V<145\end{array}$ & $V \geq 145$ \\
\hline Power $(\mathrm{kW})$ & $\leq 15$ & $>15$ & - & - & - & - \\
\hline
\end{tabular}

Table 3. Hourly billing periods depending on the type of day.

\begin{tabular}{|c|c|c|c|c|c|}
\hline \multirow{2}{*}{ Hourly Period } & \multicolumn{5}{|c|}{ Type of Day } \\
\hline & A & B & B1 & $\mathrm{C}$ & D \\
\hline $\mathrm{P} 1$ & $\begin{array}{l}09: 00-14: 00 \mathrm{~h} \\
18: 00-22: 00 \mathrm{~h}\end{array}$ & & & & \\
\hline $\mathrm{P} 2$ & $\begin{array}{l}08: 00-09: 00 \mathrm{~h} \\
14: 00-18: 00 \mathrm{~h} \\
22: 00-00: 00 \mathrm{~h}\end{array}$ & $\begin{array}{l}09: 00-14: 00 \mathrm{~h} \\
18: 00-22: 00 \mathrm{~h}\end{array}$ & & & \\
\hline P3 & & $\begin{array}{l}08: 00-09: 00 \mathrm{~h} \\
14: 00-18: 00 \mathrm{~h} \\
22: 00-00: 00 \mathrm{~h}\end{array}$ & $\begin{array}{l}09: 00-14: 00 \mathrm{~h} \\
18: 00-22: 00 \mathrm{~h}\end{array}$ & & \\
\hline $\mathrm{P} 4$ & & & $\begin{array}{l}08: 00-09: 00 \mathrm{~h} \\
14: 00-18: 00 \mathrm{~h} \\
22: 00-00: 00 \mathrm{~h}\end{array}$ & $\begin{array}{l}09: 00-14: 00 \mathrm{~h} \\
18: 00-22: 00 \mathrm{~h}\end{array}$ & \\
\hline P5 & & & & $\begin{array}{l}08: 00-09: 00 \mathrm{~h} \\
14: 00-18: 00 \mathrm{~h} \\
22: 00-00: 00 \mathrm{~h}\end{array}$ & \\
\hline P6 & 00:00-08:00 h & 00:00-08:00 h & 00:00-08:00 h & 00:00-08:00 h & All hours of day \\
\hline
\end{tabular}

The types of days for the purposes of transport and distribution tolls are, in the peninsular territory of Spain, the following [6]:

- Type A: High Season (January, February, July, and December); Monday to Friday, non-holidays.

- $\quad$ Type B: Middle-High Season (March and November); Monday to Friday, non-holidays.

- Type B1: Middle Season (June, August, and September); Monday to Friday, non-holidays.

- Type C: Low Season (April, May, and October); Monday to Friday, non-holidays.

- Type D: Saturdays, Sundays, holidays, and 6 January.

Reactive energies supplied under capacitive power factors will be penalized. These capacitive energies can occur either due to overcompensation caused by the connection of fixed capacitor banks in distribution networks, to long and little loaded lines, or to capacitive loads, such as electronic rectifiers of LED lamps, computers, etc.

Circular 3/2020 of 15 January, issued by the National Markets and Competition Commission [6], set the date of application of penalties for reactive consumptions at 1 April 2021, but it was later postponed to 1 June 2021.

Penalties for reactive energy supplies under capacitive power factors were not contemplated before the entry into force of Circular 3/2020, and are justified in the need to maintain the quality of the electrical power supply, avoiding the presence of over-voltages due to the Ferranti Effect, as well as the amplification of current harmonics caused by capacitive loads.

These penalties are applicable for consumptions at voltages higher than $1 \mathrm{kV}$ (that is, for tolls 6.1, 6.2, 6.3, and 6.4), with capacitive power factors lower than 0.98 , which take 
place between 12 a.m. and 8 a.m. (weekdays), and between 12 a.m. and 12 p.m. (holidays). The value of the power factor $(P F)$ is obtained in each hourly period as:

$$
P F=\frac{W_{p}}{\sqrt{W_{p}^{2}+W_{q}^{2}}}
$$

where $W_{p}$ is the active energy measured during the hourly period, and $W_{q}$ is the net reactive energy measured in that period obtained by the difference between the inductive and capacitive reactive energies measured in the hourly period. There will be no penalties for capacitive reactive energy if the power factor is greater than 0.98 capacitive, even if there is some capacitive reactive energies within the hourly period.

Customers pay only for the excess of capacitive reactive energy $\left(\Delta W_{q}\right)$ that reduces the power factor below 0.98 capacitive [6,31]; i.e.:

$$
\Delta W_{q}=W_{q}-0.20306 \cdot W_{p}
$$

where $W_{p}$ and $W_{q}$ are the measured active and net reactive energies, respectively.

The excesses of capacitive reactive energy $\left(\Delta W_{q}\right)$ have a penalty of EUR 0.05 per kvar-h. That is, the penalty for capacitive reactive energies $(R C A P)$ is calculated as:

$$
R C A P=0.05 \cdot \Delta W_{q}
$$

\section{Application Case}

This section describes the study carried out with the transformer of the distribution network that supplies energy to a commercial and night-entertainment area near the city of Valencia (Spain).

The manager of the distribution network was interested in this study, to assess the economic impact of new penalties for capacitive reactive energies, regulated by $\mathrm{Circu}-$ lar 3/2020 of January 15 issued by National Markets and Competition Commission [6], as well as to determine the environmental cost caused by carbon dioxide emissions into the atmosphere.

Likewise, the manager showed his interest in learning about possible solutions for reducing carbon dioxide emissions and minimizing penalties for supplying capacitive reactive energy without replacing the current transformer with a more efficient one.

The analysis of the operation of the transformer was carried out with the use of a Fluke 435 Series II analyzer in a measurement campaign lasting 4 weeks, distributed between the months of October and December 2020. This instrument has an energy loss calculator for distribution lines (Figure 1), which uses algorithms based on the expressions in Section 2 [28,32], and can be adapted to measure losses in transformers by eliminating the records in the neutral conductor and by adjusting the resistance in the energy loss calculator to the value of the short-circuit resistance of the transformer.

\subsection{Transformer Operating Analysis}

The transformer, the object of the analysis, was immersed in oil, and from the manufacturer ORMAZABAL, with a power of $1000 \mathrm{kVA}$ and nominal characteristics indicated in Table 4 . The primary was connected to the $20 \mathrm{kV}$ medium voltage electrical network. Connected to the secondary of this transformer was a three-phase bank of fixed capacitors, with a power $Q_{c 1}=3 \times 15 \mathrm{kvar}$. The transformer is placed inside of a transformation house.

Table 4. Nominal features of $1000 \mathrm{kVA}$ Ormazabal distribution transformer.

\begin{tabular}{cccc}
\hline Power (kVA) & Load Losses $(\mathbf{W})$ & No-Load Losses $(\mathbf{W})$ & Short-Circuit Resistance $(\boldsymbol{\Omega})$ \\
\hline 1000 & 10,500 & 1700 & 0.0018522 \\
\hline
\end{tabular}


The Fluke 435 Series II instrument was connected to the secondary terminals of this transformer, and measurements were made on weekdays and holidays. The active $(P)$ and reactive $\left(Q^{\prime}\right)$ powers recorded on non-holidays and holidays did not change significantly with respect to those indicated in Figures 2 and 3, respectively, throughout the different weeks in which the campaign of measurements was carried out.

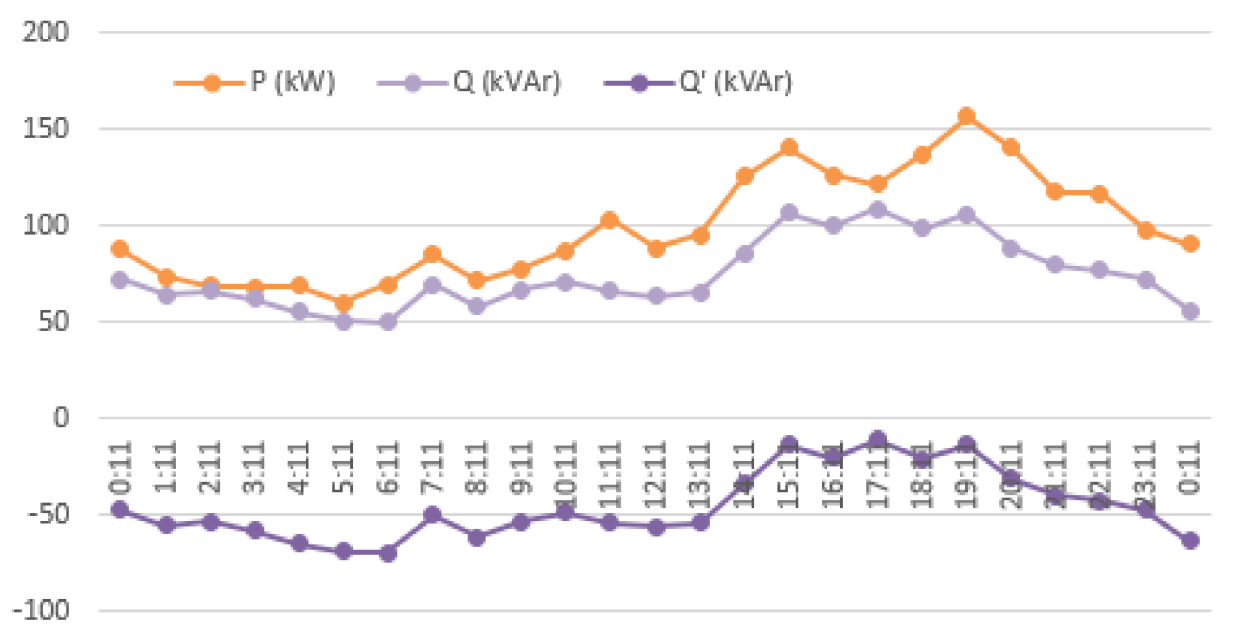

Figure 3. Powers delivered by the transformer in $24 \mathrm{~h}$ of a weekday: active $P(\mathrm{~kW})$ and reactive power $Q^{\prime}(\mathrm{kVAr})$, registered by the Fluke 435 Series II; and reactive power supplied with no capacitor banks $Q$ (kVAr) (a negative sign indicates capacitive reactive powers).

Based on the values of the reactive powers $\left(Q^{\prime}\right)$ registered by the Fluke 435 Series II analyzer, we verified that another three-phase bank of fixed capacitors, with a power of $Q_{c 2}=3 \mathrm{~h} \times 25 \mathrm{kvar}$, should have been connected to the secondary of the transformer. This second bank of capacitors was not accessible because it was outside the transformation house. These capacitor banks $\left(Q_{c 1}\right.$ and $\left.Q_{c 2}\right)$ remained connected $24 \mathrm{~h}$ a day on weekdays and holidays, giving high values of capacitive reactive power during the hours of low activity of the companies (Figures 3 and 4), and they originated large power losses due to reactive currents $\left(P_{c r}^{\prime}\right)$ in the transformer (Figures 5 and 6).

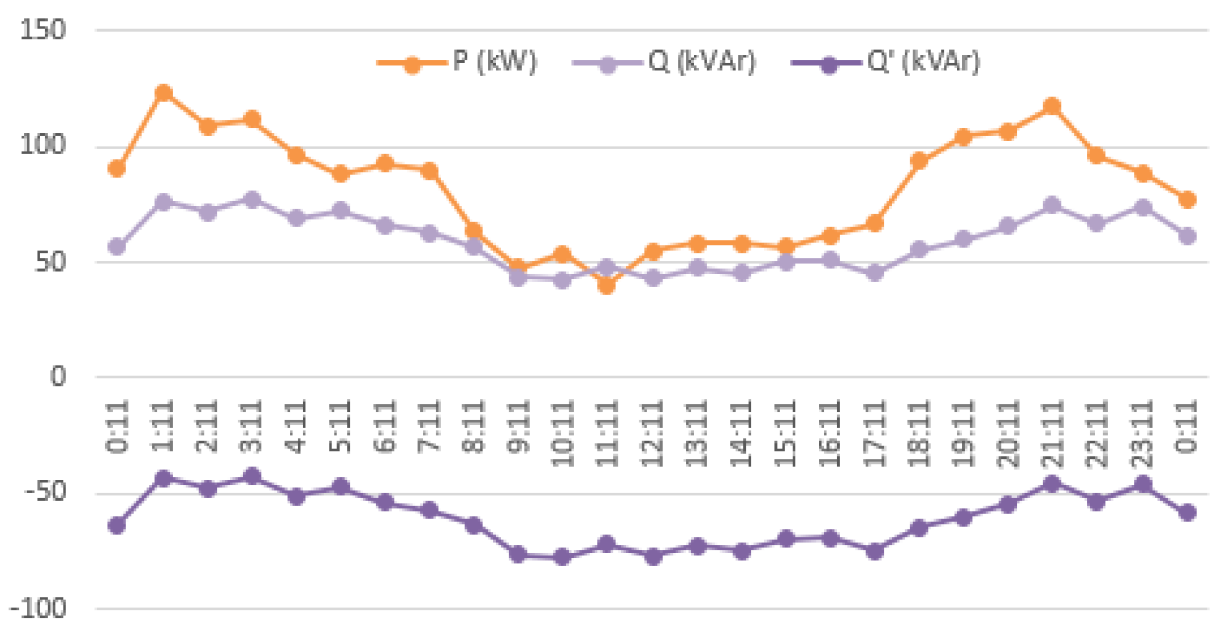

Figure 4. Powers delivered by the transformer in $24 \mathrm{~h}$ of a holiday: active $P(\mathrm{~kW})$ and reactive $Q^{\prime}(\mathrm{kVAr})$ powers registered by the Fluke 435 Series II; and reactive power supplied with no capacitor banks $Q$ (kVAr) (a negative sign indicates capacitive reactive powers). 


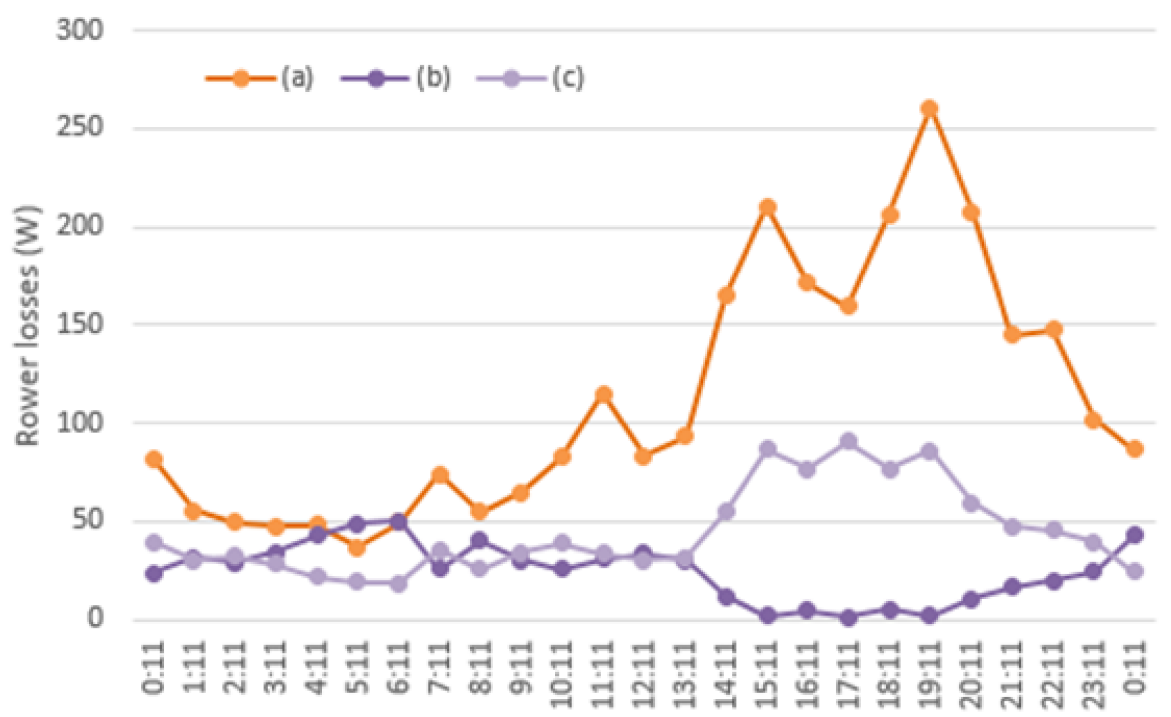

Figure 5. Transformer power losses in $24 \mathrm{~h}$ of a weekday due to: (a) active currents $\left(P_{c a}\right)$; $(\mathbf{b})$ reactive currents with capacitors $\left(P_{c r}^{\prime}\right)$; and $(\mathbf{c})$ reactive currents without capacitors $\left(P_{c r}\right)$.

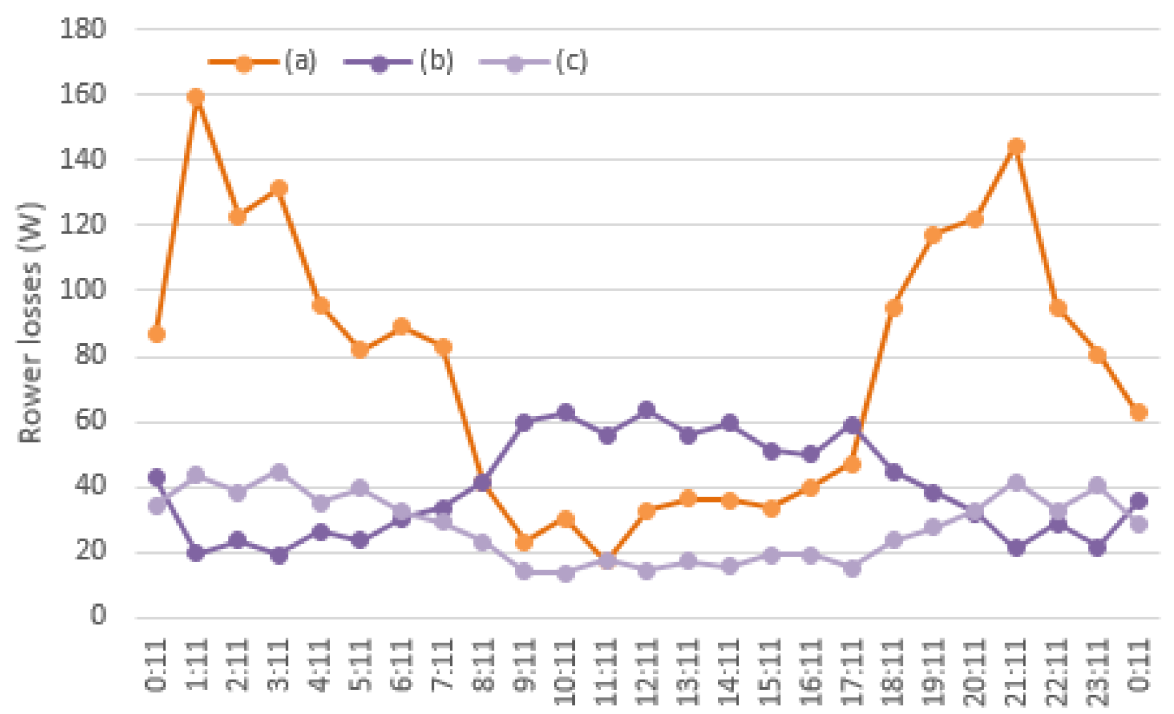

Figure 6. Transformer power losses in $24 \mathrm{~h}$ of a holiday due to: $(\mathbf{a})$ active currents $\left(P_{c a}\right)$; $(\mathbf{b})$ reactive currents with capacitors $\left(P_{c r}^{\prime}\right)$; and $(\mathbf{c})$ reactive currents without capacitors $\left(P_{c r}\right)$.

The values of the transformer power losses caused by active and reactive currents $\left(P_{c a}\right.$ y $\left.P_{c r}^{\prime}\right)$, represented in Figures 5 and 6, were measured by the Fluke 435 Series II analyzer by adjusting the resistance value to that corresponding to the short-circuit resistance of the transformer (Table 4) on the instrument's energy loss calculator screen (Figure 1). Likewise, transformer power losses due to unbalanced and distorted currents were significantly lower than those caused by reactive currents (Figures 7 and 8). 


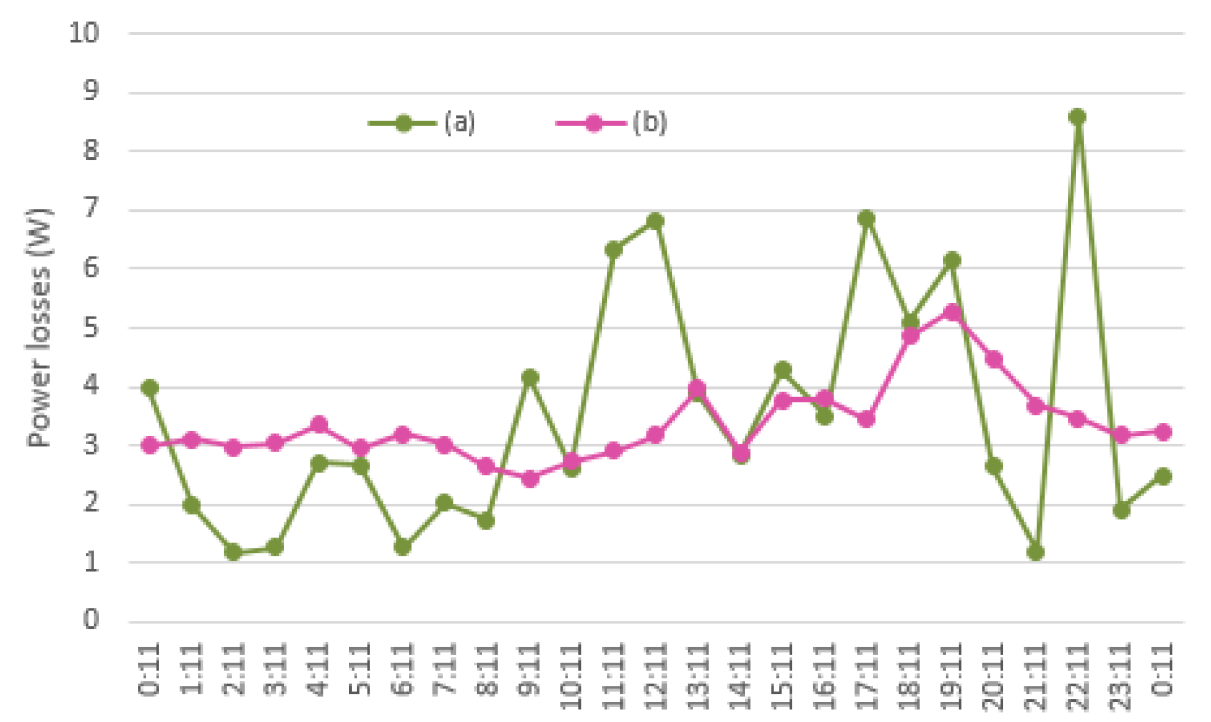

Figure 7. Transformer power losses in $24 \mathrm{~h}$ of a weekday caused by: (a) unbalanced currents $\left(P_{c u}\right)$ and (b) distorted currents $\left(P_{c h}\right)$.

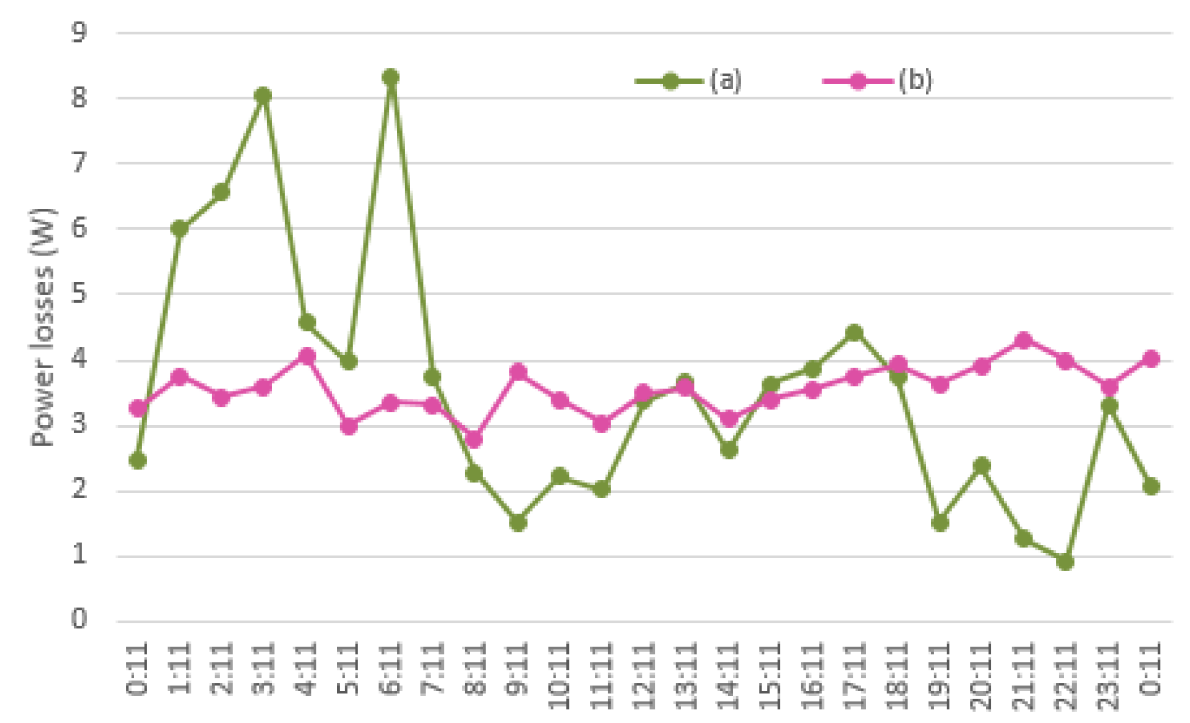

Figure 8. Transformer power losses in $24 \mathrm{~h}$ of a holiday caused by: (a) unbalanced currents $\left(P_{c u}\right)$ and (b) distorted currents $\left(P_{c h}\right)$.

\subsection{Carbon Dioxide Emissions and Penalties for Capacitive Reactive Energy}

Figures 3 and 4 show a non-suitable operation of the capacitor banks, which was worse when lowering the activity of the companies supplied by the transformer, and achieved high values of capacitive reactive power.

Consequently:

1. There were significant energy losses and high carbon dioxide emissions in the actual transformer operation with the compensating capacitors connected. Carbon dioxide emissions and reactive energy losses on holidays were lower without capacitors than with capacitor banks.

This fact can be seen in Table 5. The actual transformer losses measured on holidays, due to the reactive currents, had a value of $109.24 \mathrm{kWh} /$ year, whereas these energy losses were only $75.15 \mathrm{kWh} /$ year if the capacitor banks had not been connected. Likewise, annual carbon dioxide emissions, on holidays, were $26,327 \mathrm{~kg}$ per year with capacitor banks, compared to $18.11 \mathrm{~kg}$ per year that would be produced without capacitors. 
The carbon dioxide emissions indicated in Table 5 were determined based on the ratio $0.241 \mathrm{~kg} \mathrm{CO} 2 / \mathrm{kWh}$ (source: grid operator Red Eléctrica Española in 2019 [7]).

Table 5. Annual energy losses and $\mathrm{CO}_{2}$ emissions caused by reactive currents in the transformer operation.

\begin{tabular}{ccccc}
\hline & \multicolumn{2}{c}{ Operation with Actual Reactive Compensators } & \multicolumn{2}{c}{ Operation with No Reactive Compensators } \\
\cline { 2 - 5 } & Energy Losses $\mathbf{( k W h )}$ & $\mathbf{C O}_{\mathbf{2}}$ Emissions (kg) & Energy Losses (kWh) & $\mathbf{C O}_{\mathbf{2}}$ Emissions (kg) \\
\hline Weekdays & 149.11 & 35.937 & 449.81 & 64.63 \\
Holidays & 109.24 & 26.327 & 75.15 & 18.11 \\
\hline
\end{tabular}

2. High economic penalties for capacitive reactive energy are foreseeable, as soon as Circular 3/2020 of the Spanish National Markets and Competition Commission comes into force [6] (Table 6).

Table 6. Measured and penalized capacitive energies each day and annual penalties.

\begin{tabular}{ccccc}
\hline & \multicolumn{4}{c}{ Penalization for Capacitive Energy } \\
\cline { 2 - 5 } Type of Day & Penalty Period & $\begin{array}{c}\text { Measured Capacitive } \\
\text { Energy, } W_{\boldsymbol{q}} \\
\text { (kvar-h/day) }\end{array}$ & $\begin{array}{c}\text { Penalized Capacitive } \\
\text { Energy, } \Delta W_{\boldsymbol{q}} \\
\text { (kvar-h/day) }\end{array}$ & $\begin{array}{c}\text { Annual Penalties } \\
(\boldsymbol{R} C A P)(\text { Euros) }\end{array}$ \\
\hline Weekdays & $00: 00-08: 00 \mathrm{~h}$ & 482.81 & 367.65 & 4614.07 \\
Holidays & $24 \mathrm{~h}$ & 1452.27 & 1054.44 & 6010.28 \\
\hline
\end{tabular}

In Table 6, the supplies of capacitive reactive energy throughout a day $\left(W_{q}\right)$ are distinguished from the capacitive supplies in excess, which decrease the power factor below $0.98\left(\Delta W_{q}\right)$ measured in the penalty periods established by circular 3/2020, for weekdays and holidays. The penalties for capacitive reactive energy (RCAP) were calculated based on Equations (18) and (19) for a period of one year, between September 2020 and August 2021. In this period, there were a total 251 of weekdays and 114 holidays.

3. The transformer energy losses, as well as the carbon dioxide emissions, due to unbalance and distortion currents were much lower than these caused by the reactive currents (Table 7).

Table 7. Annual energy losses and $\mathrm{CO}_{2}$ emissions caused by imbalances and distortions in the transformer operation.

\begin{tabular}{ccccc}
\hline \multirow{2}{*}{ Type of Day } & \multicolumn{2}{c}{ Imbalance } & \multicolumn{2}{c}{ Distortion } \\
\cline { 2 - 5 } & Energy Losses $\mathbf{( k W h )}$ & $\mathbf{C O}_{\mathbf{2}}$ Emissions (kg) & Energy Losses (kWh) & $\mathbf{C O}_{\mathbf{2}}$ Emissions (kg) \\
\hline Weekdays & 21.15 & 5.097 & 20.476 & 4.935 \\
Holidays & 10.096 & 2.433 & 10.164 & 2.45 \\
\hline
\end{tabular}

5.3. Solutions for the Reduction of Carbon Dioxide Emissions and the Reduction of Costs and Penalties in the Electrical Bill

Cancelling the penalties for capacitive reactive energy, as well as for reducing losses and carbon dioxide emissions, without replacing the transformer with a more efficient one, can be carried out based on the following practical actions:

1. Optimize the operation of capacitor banks;

2. Reduce energy losses caused by unbalanced and distorted currents.

These actions can be applied jointly or separately.

5.3.1. Decarbonization Impacts Resulting of Optimizing the Operation of Capacitor Banks

As we have indicated previously, there were two fixed three-phase capacitor banks connected to the secondary of the transformer. The first, with a power $Q_{c 1}=3 \times 15 \mathrm{kvar}$, was available at the transformation house itself. The existence of the second bank of 
capacitors, of power $Q_{c 2}=3 \times 25 \mathrm{kvar}$, was deduced after the analysis of the measurements recorded by the Fluke 435 Series II analyzer.

The operation of these two capacitor banks at the same time increased the capacitive power factors, at any time of the day, both on weekdays and holidays (Figure 9). Only in the periods of activity of the companies did the power factor approach 1, but it always was within the capacitive range. In periods of low activity for companies, the power factor of the transformer registered very small values, especially on holidays (Figure 9). Consequently, carbon dioxide emissions, transformer energy losses, and penalties for capacitive reactive energy reached high values during these periods (Tables 5 and 6).

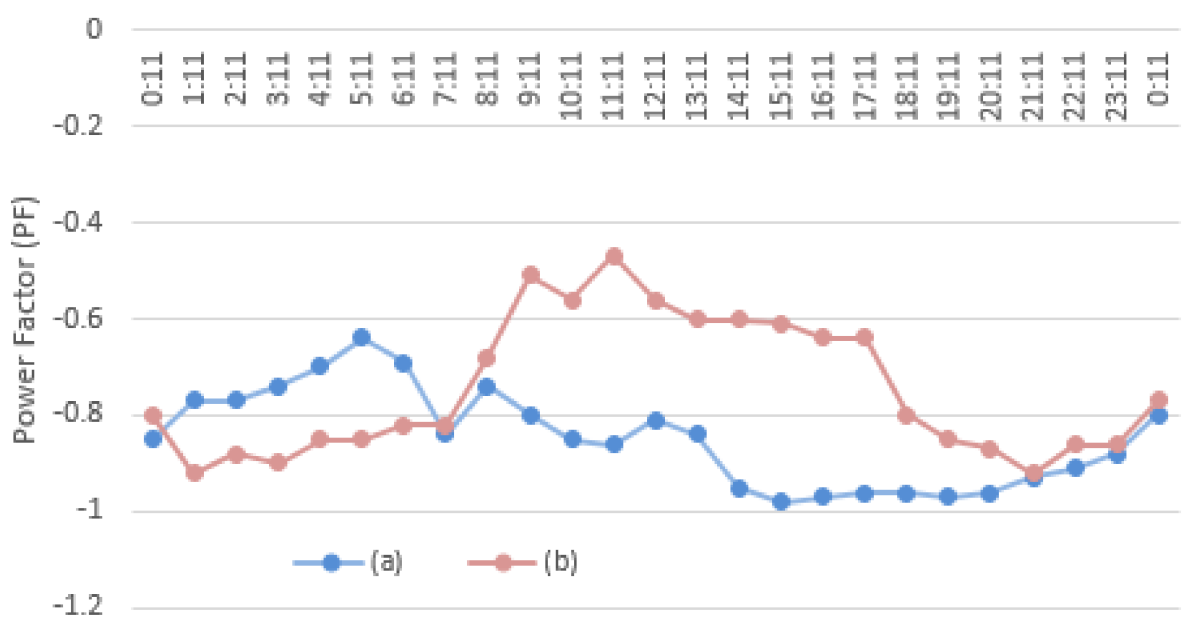

Figure 9. Transformer power factor (PF) on: (a) weekdays; and (b) holidays (positive values indicate inductive PF, whereas negative values mean capacitive PF).

To reduce these negative effects, a more suitable operation of the capacitor banks was proposed, based on two alternative optimization procedures:

(a) Keeping the first capacitor bank $\left(Q_{c 1}=3 \times 15 \mathrm{kvar}\right)$ operating only on holidays, and disconnecting the second capacitor bank $\left(Q_{c 2}=3 \times 25 \mathrm{kvar}\right)$; and on weekdays, keeping the second capacitor bank $\left(Q_{c 2}\right)$ connected and disconnecting the first one $\left(Q_{c 1}\right)$.

(b) Eliminating the first capacitor bank $\left(Q_{c 1}\right)$, and keeping the second one $\left(Q_{c 2}=3 \times 25\right.$ kvar $)$ permanently connected every day of the year.

The practical application of these optimization procedures is very cheap. For the first one, simply add a programmable timer switch to each capacitor bank. The application of the second procedure is even simpler, since it is enough to disconnect the first bank of capacitors $\left(Q_{c 1}\right)$, which is arranged next to the transformer.

When applying any of the above procedures, the transformer power factors were significantly improved, as seen in Figure 10, corresponding to procedure (a). The average power factor, as well as the total reactive energy values on weekdays and holidays, are shown in Table 8, for the first solution above. Likewise, it was possible to eliminate the penalties for capacitive reactive energy (Table 8), since the power factor in the penalty periods is inductive on weekdays, and very slightly capacitive on holidays (Table 8). 


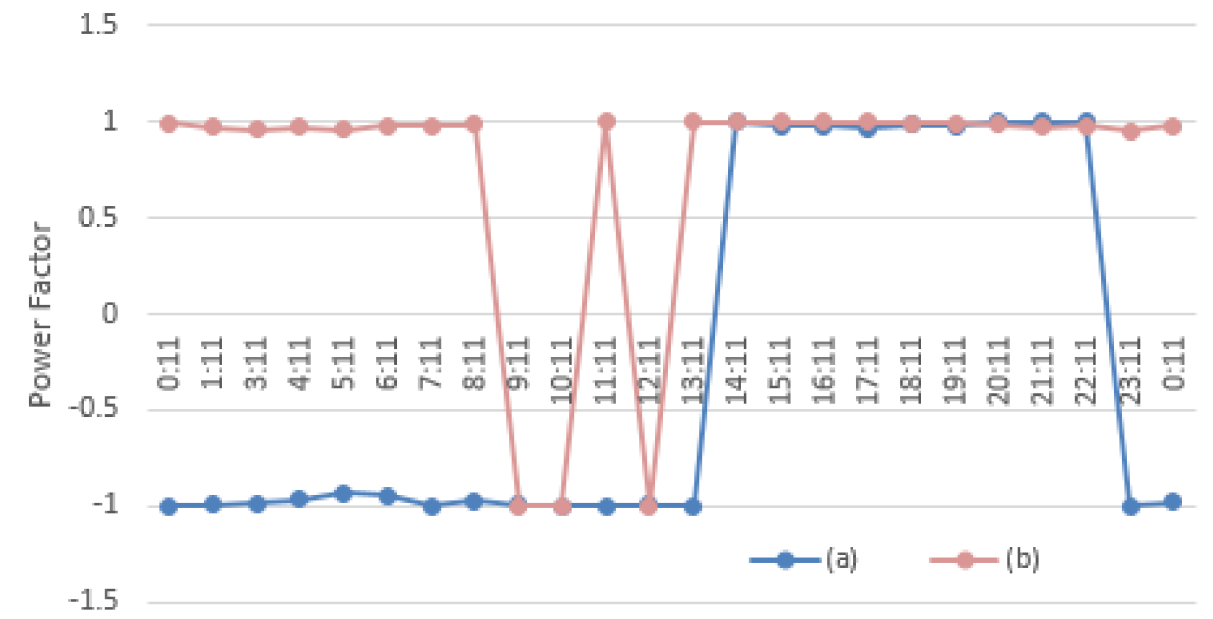

Figure 10. Transformer power factor (PF) after applying the first optimization procedure on the capacitor banks: (a) weekdays (disconnecting $Q_{c 1}$ ); (b) holidays (disconnecting $Q_{c 2}$ ).

Table 8. Daily power factor and reactive energies and annual penalizations resulting from applying the first optimization procedure on the capacitor banks $\left(Q_{c 1}\right.$ and $\left.Q_{c 2}\right)$.

\begin{tabular}{ccccc}
\hline Type of Day & Power Factor & $\begin{array}{c}\text { Total Reactive } \\
\text { Energies Per Day } \\
\text { (kvar-h) }\end{array}$ & $\begin{array}{c}\text { Penalized Capacitive } \\
\text { Energy, } \Delta W_{\boldsymbol{q}} \\
\text { (kvar-h/day) }\end{array}$ & $\begin{array}{c}\text { Annual Penalization } \\
\text { (RCAP) (Euros) }\end{array}$ \\
\hline Weekdays & -0.9999 (capacitive) & -7.917 & 0 & 0 \\
Holidays & 0.9846 (inductive) & 347.72 & 0 & 0 \\
\hline
\end{tabular}

Comparing the transformer power factors of the transformer before (Figure 9) and after (Figure 10) optimizing the operation of the capacitor banks, the transformer efficiency was greatly improved. This improvement was also observed in the large decrease in transformer power losses due to reactive currents (Figures 11 and 12).

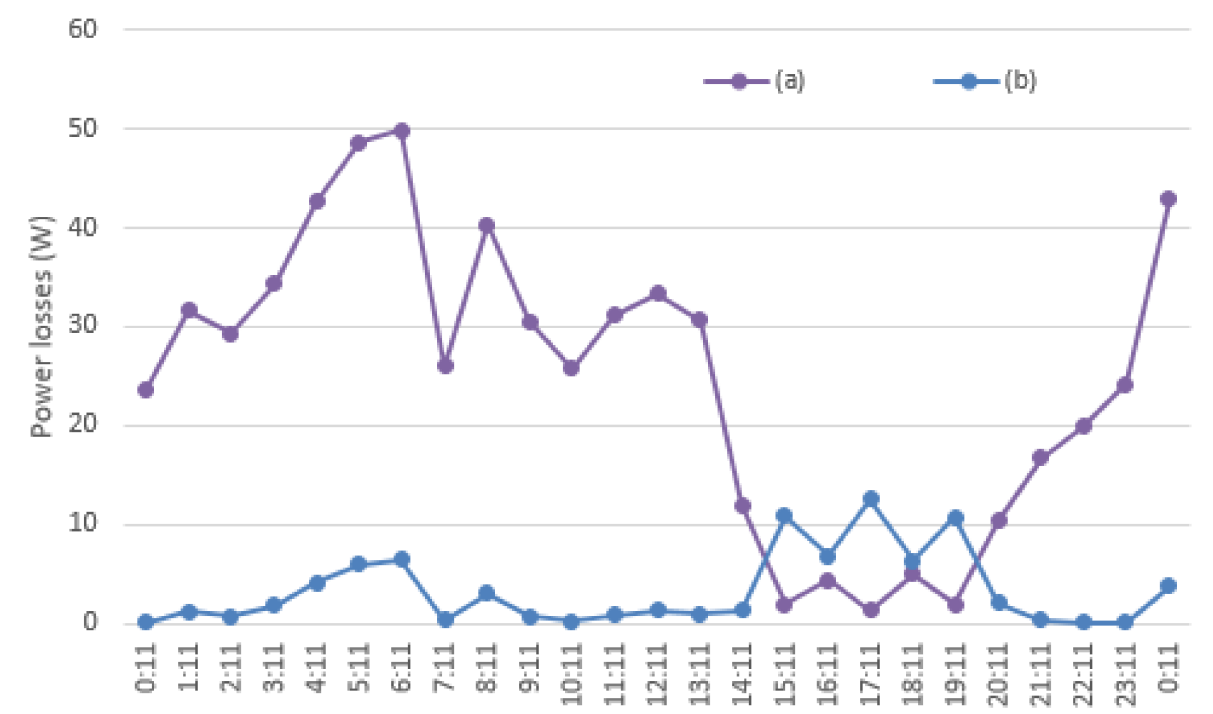

Figure 11. Transformer power losses, on weekdays, due to: (a) actual reactive currents with nonoptimized capacitors; and (b) reactive currents with capacitor banks optimized. 


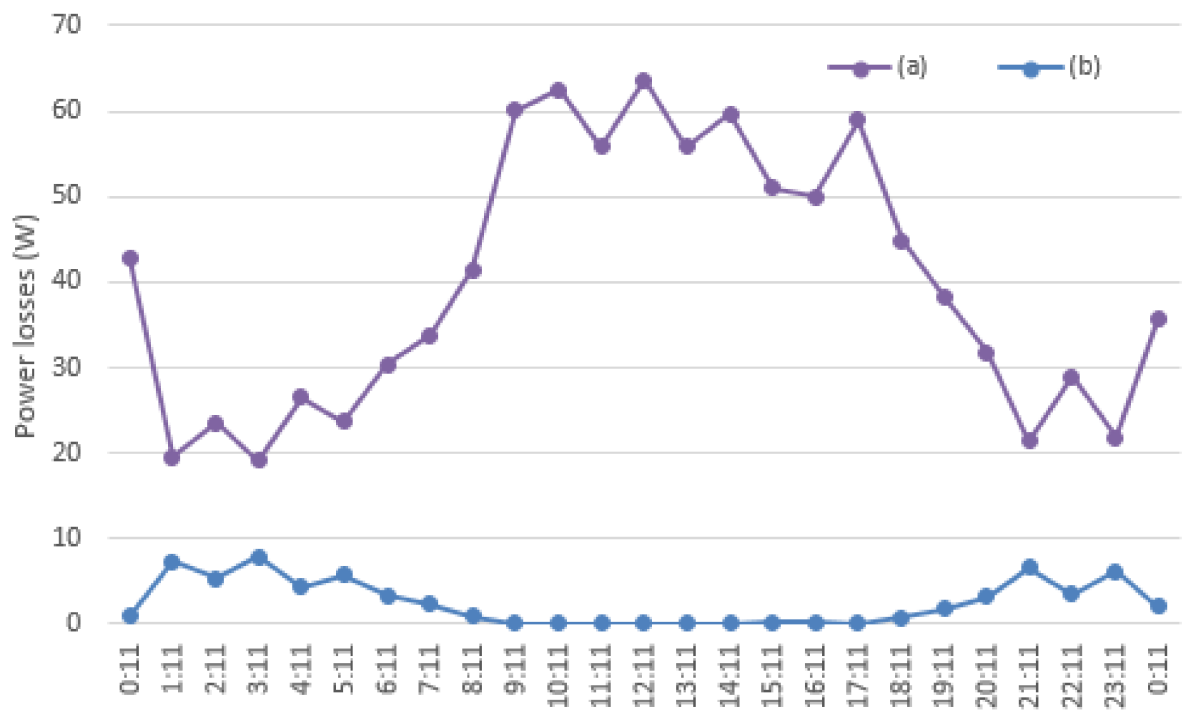

Figure 12. Transformer power losses, on holidays, due to: (a) actual reactive currents with nonoptimized capacitors; and (b) reactive currents with capacitors optimized.

The effects of optimizing the operation of the capacitor banks are also shown in Table 9. Comparing the values indicated in Table 9 with those shown in Table 5, the significant decrease in energy losses and carbon dioxide emissions in the transformer can be seen, after optimizing the operation of these reactive compensators. In addition, it can also be noted in Table 9 that the optimization procedure (a) was better than that in (b), because when the capacitor banks were optimized according to the procedure (a), the energy losses and carbon dioxide emissions reductions on holidays were larger than when using procedure (b).

Table 9. Annual energy losses and carbon dioxide emissions caused by reactive currents in the transformer operation with optimized operation of capacitor banks.

\begin{tabular}{ccccc}
\hline & \multicolumn{2}{c}{ Optimized Procedure (a) } & \multicolumn{2}{c}{ Optimized Procedure (b) } \\
\cline { 2 - 5 } & Energy Losses $\mathbf{( k W h )}$ & $\mathbf{C O}_{\mathbf{2}}$ Emissions(kg) & Energy Losses (kWh) & $\mathbf{C O}_{\mathbf{2}}$ Emissions (kg) \\
\hline Weekdays & 20.62 & 4.97 & 20.62 & 4.97 \\
Holidays & 7.66 & 1.70 & 11.086 & 2.67 \\
\hline
\end{tabular}

5.3.2. Decarbonization Impacts Resulting from Decreasing Energy Losses Caused by Unbalanced and Distorted Currents

Optimizing the operation of capacitor banks did not affect the energy losses caused by the unbalanced currents, because capacitor banks are balanced loads, but it had an additional beneficial effect on the energy losses caused by distorted currents, due to the ceasing of the amplifying effects that the capacitive loads had on these currents. These benefits are estimated to be a $25 \%$ reduction in the energy losses and carbon dioxide emissions indicated in Table 7.

Therefore, it would not be mandatory to adopt complementary actions to reduce energy losses and carbon dioxide emissions caused in the transformer by distorted currents, since their values were much lower than these produced by the reactive currents, as can be seen in Table 7 . However, it would additionally be possible to reduce at least $90 \%$ of the energy losses indicated in that table caused by distorted currents on weekdays by using passive filters tuned to the most significant harmonic frequencies (Figure 13). 


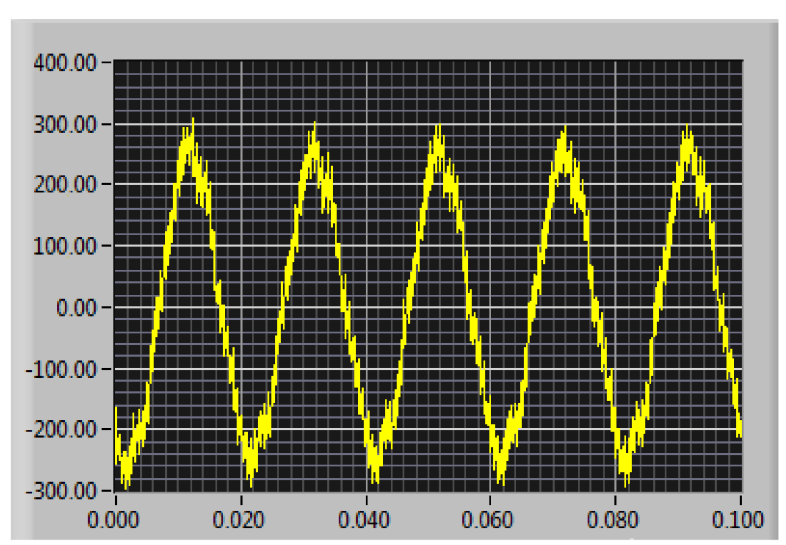

(a)

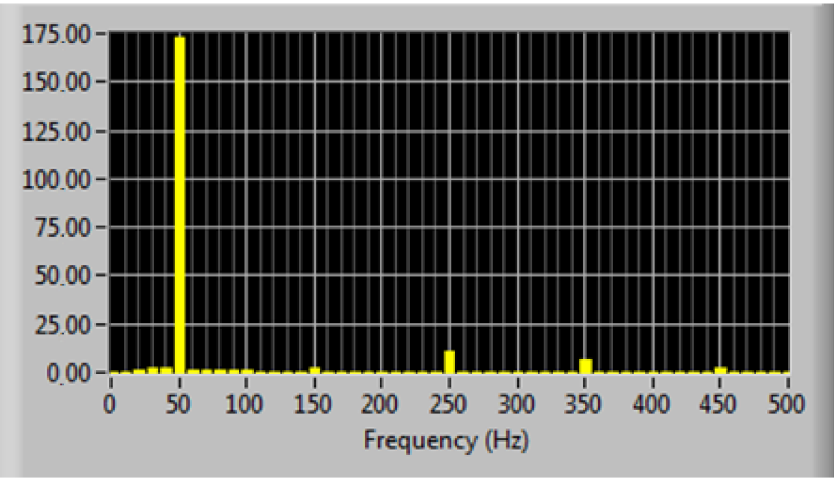

(b)

Figure 13. Current flowing through the A-phase of transformer at 16:11 on a working day: (a) waveforms; (b) harmonic diagram.

We can see in Figure $13 \mathrm{~b}$ that there were two very marked harmonic currents on weekdays, with frequencies of $250 \mathrm{~Hz}$ and $350 \mathrm{~Hz}$. Thus, in order to minimize the energy losses caused by distorted currents, the bank of capacitors $Q_{c 2}=3 \times 25 \mathrm{kvar}$ could be replaced by a three-phase harmonic filtering equipment tuned to these two frequencies. This filtering equipment must be able to provide the same reactive power as the capacitor bank $Q_{c 2}$ and, thus, it would be built by two passive three-phase, delta-configured, first-order filters, tuned to frequencies of $250 \mathrm{~Hz}$ and $350 \mathrm{~Hz}$, with reactive powers of $Q_{c 2}(250 \mathrm{~Hz})=3 \times 15 \mathrm{kvar}$ and $Q_{c 2}(350 \mathrm{~Hz})=3 \times 10 \mathrm{kvar}$, respectively.

This equipment must be permanently connected on weekdays. In each phase, a capacitor and a coil are connected in series, the values for which (Table 10) were determined by Equations (14) and (15), and must withstand harmonic currents of $250 \mathrm{~Hz}$ and $350 \mathrm{~Hz}$, respectively.

Table 10. Elements in each phase of the three-phase passive filter equipment.

\begin{tabular}{cccc}
\hline \multicolumn{2}{c}{ 250 HZ-Harmonic Filter } & \multicolumn{2}{c}{ 350 HZ-Harmonic Filter } \\
\hline$C(\mu \mathrm{F})$ & $L(\mathrm{mH})$ & $C(\mu \mathrm{F})$ & $L(\mathrm{mH})$ \\
286.49 & 1.415 & 194.88 & 1.061 \\
\hline
\end{tabular}

The connection of this harmonic filtering equipment would allow reducing energy losses and carbon emissions in the transformer due to distortion currents of $90 \%$ to $95 \%$ of the values indicated in Table 7. However, in our opinion, these benefits would not compensate for the investments in the purchase of this equipment and the replacement of capacitor banks in this application case. For this reason, we are satisfied with the $25 \%$ reduction in energy losses and carbon dioxide emissions indicated above, and maintaining the capacitor banks without replacing them with any harmonic filtering equipment.

The effects of the current imbalances on the energy losses and the emission of carbon dioxide in the transformer were smaller on public holidays than on weekdays (Table 7). These effects could be reduced by equitably distributing the active and reactive loads connected to the secondary of the transformer. For this, the vector unbalanced power $[29,30]$ can be a very useful tool, since the angles $\left(\alpha_{p}\right.$ and $\left.\alpha_{q}\right)$ of the active and reactive components $\left(\overrightarrow{S_{\text {uip }}}\right.$ and $\left.\overrightarrow{S_{\text {uiq }}}\right)$ of this vector quantity, calculated according to Equations (12) and (13), provide information about the phase or phases of the transformer in which the active and reactive powers have greater values. This information can be obtained in real time for dispatch tasks, or it can be represented throughout a measurement period, as Figure 14 represents. 


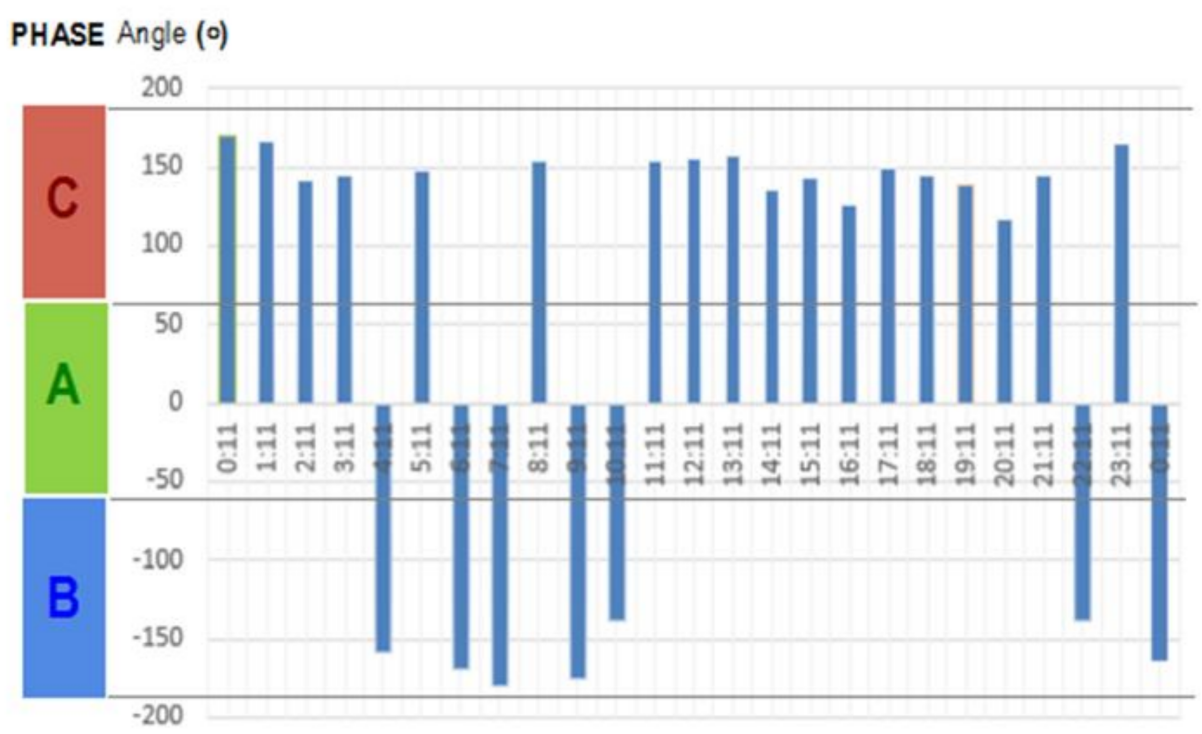

Figure 14. Representation of the transformer phases with most active powers on weekdays (the ends of the bars indicate the phase or phases that were the most unbalanced).

The values of the angles $\left(\alpha_{p}\right)$ in Figure 14 show that the largest active current unbalances were caused by the loads connected to phase $C$, while the smallest unbalances were those caused by the active powers consumed by the loads connected to phase A at any time on weekdays. For this reason, reducing the effects of active current imbalances in the transformer could be achieved by changing some users from phase $\mathrm{C}$ and connecting them to phase $\mathrm{A}$, whenever this distribution is possible.

The improvement of energy losses and carbon dioxide emissions caused by the unbalanced currents is more difficult to quantify than reactive and distorted currents, as it depends on the possibility of a better distribution of the loads connected to the secondary of the transformer.

\subsection{Economic Cost of Energy Losses}

Transformer losses are energy consumptions, and therefore increase carbon dioxide and other gas emissions into the atmosphere. However, they also involve economic costs, which must be borne by the manager of the electrical network. In this section, these costs are determined for the $1000 \mathrm{kVA}$ Ormazabal transformer, the object of the study, operating in two scenarios:

- Under the current operating conditions of the transformer, without applying any improvement action, and;

- Optimizing the operation of capacitor banks and considering a $25 \%$ reduction in energy losses caused by harmonics, while not incorporating any filtering equipment, to avoid investments.

The economic costs of the energy losses of the transformer are included in the energy billing term (FE) of the electricity bill, and their value is obtained according to Equation (16). The price of electricity firstly depends on the type of toll (Table 1) and the time of day when the consumption is made. Three types of consumption are distinguished in each season of the year (Table 3): peak (from 9 a.m. to 2 p.m. and from 6 p.m. to 10 p.m.), flat (from 9 a.m. to 10 a.m., from 2 p.m. to 6 p.m., and from 10 p.m. to midnight) and valley (from 12 a.m. to 8 a.m., on weekdays, and all hours on holidays). In addition, energy prices are not the same every day of the year. Five seasons are distinguished per year (Table 3): high (A), medium-high (B), medium (B1), low (C), and holidays, including Saturdays and Sundays (D). Taking into account each of these seasons, electricity prices have different values, both in peak hours, as in flat hours and in valley hours. 
In the present study, the energy prices in each period were those indicated in Table 1 for toll 6.1 TDA (NT1), with supply voltages between $1 \mathrm{kV}$ and $30 \mathrm{kV}$ (Table 2). These prices are available, in summary, in Table 11, for type of hour layer (peak, flat, and valley) and season of the year (A, B, B1, C, and D).

Table 11. Price of energy, in euros per kWh, as a function of the type of time and the season. (1) Number of days between September 2020 and August 2021.

\begin{tabular}{ccccc}
\hline \multirow{2}{*}{ Season } & N $^{\mathbf{0}}$ of Days $^{(\mathbf{1})}$ & \multicolumn{3}{c}{ Type of Time } \\
\cline { 3 - 5 } & & Peak & Plain & Valley \\
\hline A & 81 & 0.03295 & 0.024407 & 0.002636 \\
B & 43 & 0.024407 & 0.01318 & 0.002636 \\
B1 & 66 & 0.01318 & 0.00659 & 0.002636 \\
C & 61 & 0.00659 & 0.004224 & 0.002636 \\
D & 114 & - & - & 0.002636 \\
\hline
\end{tabular}

The daily energy consumption due to the full energy losses in the transformer (load plus core power losses) are summarized in Table 12 for scenarios (a) and (b). It can be deduced from Table 12 that the daily total energy consumption in the transformer without improvement actions was $44,277 \mathrm{kWh}$, whereas the daily consumption when optimizing the operation of the capacitor banks was reduced to $43,704 \mathrm{kWh}$ on weekdays. On public holidays, daily energy consumption went from $43,748 \mathrm{kWh}$ without optimization to $42,787 \mathrm{kWh}$ optimized. In other words, an annual savings of $143.851 \mathrm{kWh}$ was achieved on weekdays, and $109.554 \mathrm{kWh}$ on public holidays (Table 12). These were energy savings due to only current reductions, because the transformer core losses remained (since the transformer was not changed in this study). The cost savings resulting from these energy savings were much more modest; of only EUR 1.71/year (Table 12).

Table 12. Daily energy consumptions and annual costs of the $1000 \mathrm{kVA}$ Ormazabal transformer with and without optimized operation. ${ }^{(1)}$ Weekdays and ${ }^{(2)}$ holidays.

\begin{tabular}{|c|c|c|c|c|c|}
\hline \multirow{2}{*}{$\begin{array}{l}\text { Type of Day } \\
\text { (n }{ }^{\circ} \text { Days) }\end{array}$} & \multirow[b]{2}{*}{ Period } & \multicolumn{2}{|c|}{ Non-Optimized Transformer } & \multicolumn{2}{|c|}{ Optimized Transformer } \\
\hline & & $\begin{array}{c}\text { Daily Consumption } \\
(\mathbf{k W h})\end{array}$ & $\begin{array}{l}\text { Annual Costs } \\
\text { (euros) }\end{array}$ & $\begin{array}{c}\text { Daily Consumption } \\
(\mathrm{kWh})\end{array}$ & $\begin{array}{l}\text { Annual Costs } \\
\text { (euros) }\end{array}$ \\
\hline \multirow{2}{*}{$\mathrm{A}(81)$} & Peak (P1) & 16.85478 & \multirow{2}{*}{70.81} & 16.6663405 & \multirow{2}{*}{70.14} \\
\hline & Plain (P2) & 13.06482 & & 12.9774807 & \\
\hline \multirow{2}{*}{ B (43) } & Peak (P2) & 16.85478 & \multirow{2}{*}{25.10} & 16.6663405 & \multirow{2}{*}{24.85} \\
\hline & Plain (P3) & 13.06482 & & 12.9774807 & \\
\hline \multirow{2}{*}{ B1 (66) } & Peak (P3) & 16.85478 & \multirow{2}{*}{20.34} & 16.6663405 & \multirow{2}{*}{20.14} \\
\hline & Plain (P4) & 13.06482 & & 12.9774807 & \\
\hline \multirow{2}{*}{$C(61)$} & Peak (P4) & 16.85478 & \multirow{2}{*}{10.14} & 16.6663405 & \multirow{2}{*}{10.04} \\
\hline & Plain (P5) & 13.06482 & & 12.9774807 & \\
\hline $\mathrm{D}\left(251^{(1)}+114\right.$ & Valley (P6) & 14.35772 & 9.50 & 14.060388 & 9.30 \\
\hline$(2)$ & Valley (P6) (2) & 43.74819 & 13.15 & 42.7874907 & 12.86 \\
\hline TOTAL & ALL & & 149.04 & & 147.33 \\
\hline
\end{tabular}

\subsection{Summary of Savings in Carbon Dioxide Emissions and in Economic Costs}

Table 13 summarizes the transformer savings in energy consumption, in carbon emissions into the atmosphere, and in operating costs, both due to the reduction in energy consumption of the transformer and savings due to penalties for reactive energy supplies with capacitive power factors. 
Table 13. Summary of 1000 kVA Ormazabal transformer savings in energy losses, carbon dioxide emissions, and economic costs.

\begin{tabular}{ccccc}
\hline & $\begin{array}{c}\text { Power Losses } \\
(\mathbf{k w h})\end{array}$ & $\begin{array}{c}\text { Carbon Dioxide Emissions } \\
\mathbf{( k g )}\end{array}$ & \multicolumn{2}{c}{ Costs (Euros) } \\
\cline { 3 - 5 } & 143.851 & 34.668 & 1.42 & Consumptions (FE) \\
\hline Working days & 109.554 & 26.402 & 0.29 & 4614.07 \\
Non-working days & 253.405 & 61.07 & 1.71 & 6010.28 \\
Total & & $10,624.35$ & Penalties \\
\hline
\end{tabular}

\section{Conclusions}

Decreasing the reactive, unbalanced and distorted currents that flow through the transformer windings using optimization techniques well known in industrial practice, such as reactive power compensation, equal load distribution, and/or harmonic filtering, can be an acceptable solution to improve energy sustainability and carbon dioxide emissions, as long as current inefficient transformers cannot be replaced by other more efficient ones.

The impact of these optimization actions can be evaluated based on three aspects, mainly: (1) savings in energy consumption; (2) reduction of greenhouse gas emissions; and (3) savings in economic costs and penalties. The energy savings are obtained by comparing the transformer energy consumptions before and after the application of techniques and devices to improve the transformer efficiency. The reduction of carbon dioxide and other gas emissions, which affect the environment, depends on the reduction of the energy consumed by transformers, as well as on the energy mix, which takes into account the generation of electricity using clean energy and fossil fuels; for this reason, it has different values for each country and each year. The savings in economic costs are more difficult to determine, since the consumption made in each hourly period must be counted, with different energy prices for each time of the year established by the government of each country. In Spain, the determination of these costs and the penalties for reactive energy is currently carried out based on Circular 3/2020 of the Markets and Competition Commission [6].

The application in this paper of actions to reduce currents in a distribution transformer that supplies an actual commercial and night-entertainment area revealed that the energetic sustainability of that transformer was improved by optimizing only the operation of the existing capacitor banks, and without adopting other actions for improving imbalances and distortions; therefore, practically at zero cost. Specifically, the transformer energy consumptions were reduced by an amount of $253.4 \mathrm{kWh} /$ year, the carbon dioxide emissions were decreased by $61.07 \mathrm{~kg} /$ year, and the penalty savings for supplies under capacitive power factors were EUR 10,624.35/year (Table 13). The cost savings of the energy consumed by the transformer were much more modest, and amounted to only EUR 1.71/year. These energetic, environmental, and economic benefits were obtained in an application case in Spain. However, these results can be generalized to any transformer in any country simply by using the value of the short-circuit resistance of the corresponding transformer, as well as the coefficient of carbon dioxide emissions and the electricity prices of each country. These benefits can be especially useful for electricity utilities and owners of transformation houses, since they reduce the carbon footprint and operating costs of their companies.

The studies carried out on transformers of other transformation houses, which were not included in this paper, revealed that the adequate compensation of reactive power was usually the main sustainability action in distribution transformers, based on current reductions. The energy savings produced by reactive power compensation, as well as the reduction of carbon dioxide emissions and economic costs due to penalties, were generally much higher than those achieved by compensating load unbalances and harmonic distortions.

In addition to improving sustainability in distribution transformers based on reducing the currents in their windings, another option to increase the decarbonization impacts would have been reducing the core power losses in these transformers. The last option was not an object of study of this paper and could be carried out replacing the actual inefficient transformer by another more efficient one, which would mean making important 
economic investments. These two options for improving the sustainability of distribution transformers (minimizing currents and reducing core losses) are complementary ones, and their benefits are added when both are applied at once.

In advance of what will be described in a future paper, a more efficient transformer of only $630 \mathrm{kVA}$ could replace the inefficient $1000 \mathrm{kVA}$ Ormazabal transformer studied in this paper. According to [10], from 1 July 2021, this efficient transformer would have nominal load losses of only $4600 \mathrm{~W}$, compared to $10,500 \mathrm{~W}$ for the $1000 \mathrm{kVA}$ inefficient transformer, and core losses of $540 \mathrm{~W}$, against no-load losses of $1700 \mathrm{~W}$ from the $1000 \mathrm{kVA}$ inefficient transformer. As a result, a reduction in losses of $9982 \mathrm{kWh}$ is expected, which would represent a reduction of $62 \%$ in energy losses after the change in transformers. The reduction in carbon dioxide emissions would be $2405.65 \mathrm{~kg} \mathrm{CO}_{2} /$ year $(62 \%)$. The cost savings derived from these consumptions would be EUR 93.2/year, compared to EUR $1.71 /$ year with the current transformer. The penalties for capacitive reactive deliveries would not be affected by the replacement of the transformers, maintaining savings of EUR $10,624.35$ per year.

Author Contributions: Conceptualization, V.L.-M.; methodology, V.L.-M.; validation, V.L.-M., C.A.M., L.M.-C., J.C.-M. and E.P.-L.; resources, V.L.-M., C.A.-M., L.M.-C., J.C.-M. and E.P.-L.; data curation, V.L.-M., C.A.-M., L.M.-C., J.C.-M. and E.P.-L.; writing-original draft preparation, V.L.-M.; writingreview and editing, C.A.-M., L.M.-C., J.C.-M. and E.P.-L.; supervision, V.L.-M.; project administration, E.P.-L. and V.L.-M.; funding acquisition, E.P.-L. All authors have read and agreed to the published version of the manuscript.

Funding: This research was funded by Generalitat Valenciana (grant number GV/2021/149) and the H2020 project SMEmPower (grant number 847132). The APC was funded by Generalitat Valenciana.

Institutional Review Board Statement: Not applicable.

Informed Consent Statement: Not applicable.

Data Availability Statement: Not applicable.

Conflicts of Interest: The authors declare no conflict of interest. The funders had no role in the design of the study; in the collection, analyses, or interpretation of data; in the writing of the manuscript; or in the decision to publish the results.

\section{References}

1. U4E. Accelerating the Global Adoption of Energy-Efficient Transformers; UN Environment. Economy Division. Energy \& Climate Branch: Paris, France, 2017.

2. Energy Efficient Distribution Transformers. 2017. Available online: https://leonardo-energy.pl/wp-content/uploads/2017/08/ Energy-efficient-distribution-transformers.pdf (accessed on 30 August 2021).

3. Al-Badi, A.H.; Elmoudi, A.; Metwally, I.; Al-Wahaibi, A.; Al-Ajmi, H.; Al Bulushi, M. Losses Reduction in Distribution Transformers. In Proceedings of the International MultiConference of Engineers and Scientists 2011, IMCES 2011, Hong Kong, China, 16-18 March 2011; Volume II, ISBN 978-988-19251-2-1.

4. Olivares, J.C.; Liu, Y.; Cañedo, J.M.; Escarela-Pérez, R.; Driesen, J.; Moreno, P. Reducing Losses in Distribution Transformers. IEEE Trans. Power Deliv. 2003, 18, 821-825. [CrossRef]

5. Energy Efficient Distribution Transformers. HPS-Hammond Power Solutions Inc. Available online: www.hammondpowersolutions.com (accessed on 30 August 2021).

6. Circular 3/2020, of January 15, of the National Markets and Competition Commission, which establishes the methodology for calculating electricity transmission and distribution tolls. Span. Off. State Bull. (BOE) 2020, 21, 6953-6980. Available online: https: / / www.boe.es (accessed on 30 August 2021).

7. Sustainability Report 2020. Red Eléctrica, Spanish Operator. 21 April 2021. Available online: https://www.ree.es/es/ publicaciones /informe-sostenibilidad-2020 (accessed on 30 August 2021).

8. EPA. 2019 US Weighted Average Marginal CO2 Emission Rate Data; US Environmental Protection Agency: Washington, DC, USA, 2019. Available online: https / /:www.energy-and-the-environment/greenhouse-gas-equivalency-calculator (accessed on 30 August 2021).

9. Tran, Q.T.; Davies, K.; Roose, L.; Wiriyakitikun, P.; Janjampop, J.; Sanseverino, E.R.; Zizzo, G. A Review of Health Assessment Techniques for Distribution Transformers in Smart Distribution Grids. Appl. Sci. 2020, 10, 8115. [CrossRef] 
10. Commission Regulation (EU) No 548/2014 of 21 May 2014 on Implementing Directive 2009/125/EC of the European Parliament and of the Council with Regard to Small, Medium and Large Power Transformers. Available online: https:/ / eur-lex.europa.eu/ legal-content/EN/TXT/PDF/?uri=CELEX:32014R0548\&from=EN (accessed on 30 August 2021).

11. Commission Regulation (EU) 2019/1783 of 1 October 2019 Amending Regulation (EU) No 548/2014 on Implementing Directive 2009/125/EC of the European Parliament and of the Council with Regard to Small, Medium and Large Power Transformers. Available online: https:/ / eur-lex.europa.eu/legal-content/EN/TXT/?uri=CELEX\%3A32019R1783 (accessed on 30 August 2021).

12. ANSI. American National Standard for Transformers-Standard for Overhead Type Distribution Transformers, 500 kVA and Smaller: High Voltage 34500 Volts and Below: Low Voltage, 7970/13800Y Volts and Below. In ANSI C57.12.20-1997; ANSI: New York, NY, USA, 2002; pp. 1-51.

13. IEEE Guide for Loading Mineral-Oil-Immersed Transformers-Corrigendum1. In IEEE Std C57.91-1995/Cor 1-2002; IEEE: New York, NY, USA, 2003; pp. 1-16.

14. IEEE Guide for Loading Mineral-Oil-Immersed Transformers and Step-Voltage Regulators. In IEEE Std C57.91-2011 (Revision of IEEE Std C57.91-1995); IEEE: New York, NY, USA, 2012; pp. 1-123.

15. IEC Standard 60422:2013. Mineral Insulating Oils in Electrical Equipment_Supervision and Maintenance Guidance; IEC-Fluids for Electrotechnical Applications Technical Committee: Geneva, Switzerland, 2013.

16. Energy Efficient Transformers: European Minimum Energy Performance Regulation (MEPS). Available online: www.abb.com/transformers (accessed on 30 August 2021).

17. Directive 2009/125/EC of the European Parliament and of the Council of 21 October 2009 Establishing a Framework for the Setting of Eco-Design Requirements for Energy-Related Products. Available online: https:/ / eur-lex.europa.eu/LexUriServ/ LexUriServ.do?uri=OJ:L:2009:285:0010:0035:en:PDF (accessed on 30 August 2021).

18. NEMA Premium ${ }^{\circledR E}$ Efficiency Transformer Program. Available online: http://www.nema.org/Technical/Pages/NEMA-PremiumEfficiency-Transformers-Program.aspx (accessed on 30 August 2021).

19. IEC TS 60076-20:2017. Power Transformers-Part 20: Energy Efficiency. 30 January 2017. Available online: https:/ webstore.iec. ch/publication/28063 (accessed on 30 August 2021).

20. Garcia, D.; Valencia, J.; Hausman, G. U.S. Department of Energy's 2016 Transformer Efficiency Changes and Impact on Inrush Current for Low Voltage Dry-Type Transformers. EATON. April 2016. Available online: www.eaton.com (accessed on 30 August 2021).

21. de Almeida, A.; Santos, B.; Martins, F. Energy-efficient distribution transformers in Europe: Impact of Ecodesign regulation. Springer Science+Business Media Dordrecht 2015. Energy Effic. 2016, 9, 401-424. [CrossRef]

22. Tapan Kumar, S.; Prithwiraj, P. Smart Transformer Condition Monitoring and Diagnosis. In Transformer Ageing: Monitoring and Estimation Techniques; Wiley-IEEE Press: Piscataway, NJ, USA, 2017.

23. Lezhniuk, P.D.; Rubanenko, O.E.; Rubanenko, O.O. Determination of Optimal Transformation Ratios of Power System Transformers in Conditions of Incomplete Information Regarding the Values of Diagnostic Parameters. In Fuzzy Logic; IntechOpen: London, UK, 2019. [CrossRef]

24. Fortescue, C.L. Method of symmetrical coordinates applied to solution of poly-phase networks. In Proceedings of the 34th Convention of American Institute of Electrical Engineers, Atlantic City, NJ, USA, 28 June 1918. [CrossRef]

25. CFR Title 10 Chapter II Part 431, Energy Efficiency Program for Certain Commercial and Industrial Equipment, Appendix A of Subpart K-Distribution Transformers. US Regulations. 2016. Available online: https://www.govinfo.gov/app/details/CFR-2016 -title10-vol3/CFR-2016-title10-vol3-part431-subpartK (accessed on 30 August 2021).

26. Baggini, A. Overview of IEC/TS 60076-20 Ed. 1.0: Power Transformers-Part 20: Energy Efficiency. In Proceedings of the Workshop on Reducing Losses in Power Distribution through Improved Efficiency of Distribution Transformers, Jeju, Korea, 28 March 2017.

27. IEEE Standard 1459-2010. IEEE Trial Use Standard for the Measurement of Electric Power Quantities under Sinusoidal, Non-Sinusoidal, Balanced or Unbalanced Conditions; IEEE Power and Energy Society: New York, NY, USA, 2010.

28. FLUKE. The Costs of Poor Power Quality. Application Note. Fluke Corporation. December 2011. Available online: https: / / assets.testequity.com/te1/Documents/pdf/poor-power-quality-costs.pdf (accessed on 30 August 2021).

29. León-Martínez, V.; Montañana-Romeu, J. Formulations for the apparent and unbalanced power vectors in three-phase sinusoidal systems. Electr. Power Syst. Res. 2018, 160, 37-43. [CrossRef]

30. León-Martínez, V.; Montañana-Romeu, J. Method and System for Measuring Imbalances in an Electrical Grid. European Patent Application EP3232207A1, 18 October 2017.

31. New Penalties for Capacitive Reactive Energy. April 2020. Available online: www.casel.es (accessed on 30 August 2021). (In Spanish).

32. FLUKE. The Valencia Algorithm: Calculating Costs of Energy Loss due to Poor Power Quality. Application Note. Fluke Corporation. 2012. Available online: http:/ / www.fluke.co.uk (accessed on 30 August 2021). 